\title{
ÓlEO DE SOJA, ÓLEO ÁCIDO DE SOJA E SEBO BOVINO COMO FONTES DE GORDURA EM RAÇÕES PARA FRANGOS DE CORTE
}

\author{
JULIANO BENEDITO GAIOTTO \\ Engenheiro Agrônomo
}

Orientador: Prof. Dr. JOSÉ FERNANDO MACHADO MENTEN

Dissertação apresentada à Escola Superior de Agricultura "Luiz de Queiroz", Universidade de São Paulo, para obtenção do título de Mestre em Agronomia, Área de Concentração: Ciência Animal e Pastagens.

PIRACICABA

Estado de São Paulo - Brasil

Maio - 2000 


\section{Dados Internacionais de Catalogação na Publicação (CIP) DIVISÃO DE BIBLIOTECA E DOCUMENTAÇĀO - Campus "Luiz de Queiroz"/USP}

\section{Gaiotto, Juliano Benedito}

Óleo de soja, óleo ácido de soja e sebo bovino como fontes de gordura em raçōes para frangos de corte / Juliano Benedito Gaiotto. - - Piracicaba, 2000.

$56 \mathrm{p}$.

Dissertação (mestrado) - - Escola Superior de Agricultura Luiz de Queiroz, 2000. Bibliografia.

1. Ácido graxo 2. Composição corporal 3. Frango de corte 4. Gordura 5. Nutrição animal 6. Óleo de soja 7. Ração animal I. Título

CDD 636.513 
Dedico

Aos meus amados pais Luiz e Teresa e ao meu querido irmão Daniel pelo amor e carinho recebido em toda minha vida.

Ofereço

Aos meus avós Dalila e Luis, Mário e Luiza por quem tenho admiração, respeito e carinho. 


\section{AGRADECIMENTOS}

À DEUS.

Ao Prof Dr José Fernando Machado Menten pela amizade e sabedoria transmitida de forma serena e paciente durante o curso de mestrado.

Ao Prof. Dr Roberto Dias de Moraes e Silva pelo apoio, compreensão e confiança desde o curso de graduação.

À fundação de Amparo à Pesquisa do Estado de São Paulo (FAPESP) pelo financiamento do projeto e pela bolsa concedida.

Aos amigos Aline, Márcia, Paulo e Adriana pela amizade e incentivo durante todo o curso de mestrado.

À todos os professores do Departamento de Produção Animal pelos ensinamentos durante o curso de mestrado.

À professora Marisa A. B. Regitano D'Arce pelas sugestões e utilização do laboratório de Óleos e Gorduras.

À professora Maria Cristina Stolf Nogueira pela atenção e orientação na análise estatística. 
Ao Ricardo Cavalcanti Martino, pesquisador da Unidade de Tecnologia do Pescado/FIPERJ, pela ajuda e prontidão nas análises dos ácidos graxos.

Às secretárias Vera e Cláudia do Departamento de Produção pela amizade e ajuda em todos os momentos.

À Granol Alimentos S.A. pelo fornecimento do óleo ácido de soja.

À Guyomarc'h do Brasil pela doação dos premixes vitamínicos e minerais.

Aos funcionários do Departamento de Produção Animal, especialmente ao Alexandre, ao Chico, ao Augusto e ao Antônio Carlos pela ajuda concedida durante estes anos.

A todos que de alguma maneira auxiliaram na realização deste trabalho. 


\section{SUMÁRIO}

Página

LISTA DE TABELA ........................................................................ iii

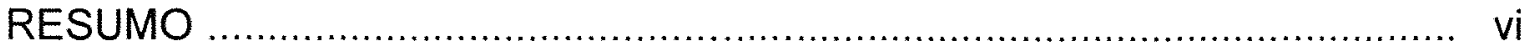

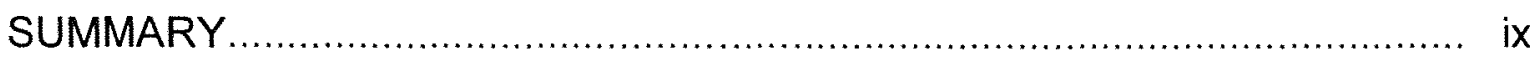

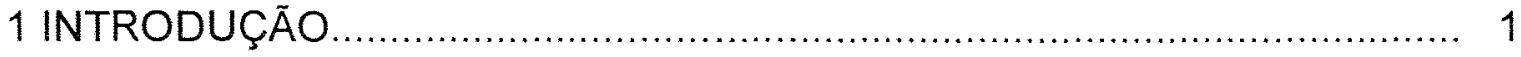

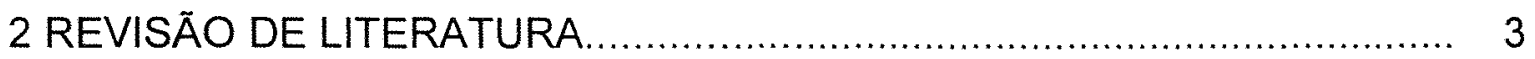

2.1 Utilização das gorduras............................................................... 3

2.2 Digestão e absorção das gorduras................................................... 4

2.3 Absorção na fase inicial de desenvolvimento das aves........................ 5

2.4 Influência dos ácidos graxos livres na absorção de gorduras................. 6

2.5 Influência da proporção de ácidos insaturados e saturados na absorção de gorduras...................................................................... 8

2.6 Fatores que interferem na determinação da energia........................... 10

2.7 Qualidade da carcaça das aves................................................... 10

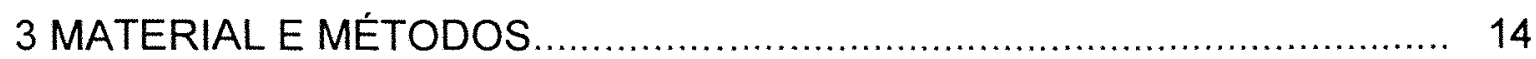

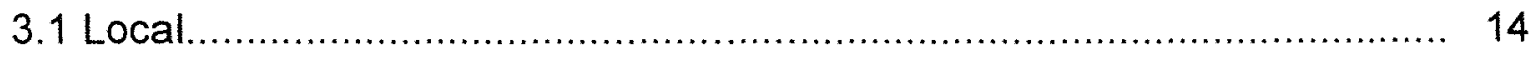

3.2 Instalações e Metodologia Experimental............................................ 14

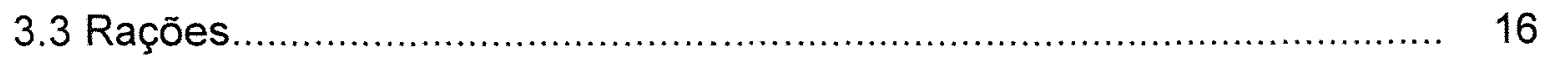

3.4 Fontes de gordura utilizadas .................................................. 18

3.5 Delineamento Experimental e Tratamentos..................................... 19

3.6 Variáveis Dependentes............................................................. 19

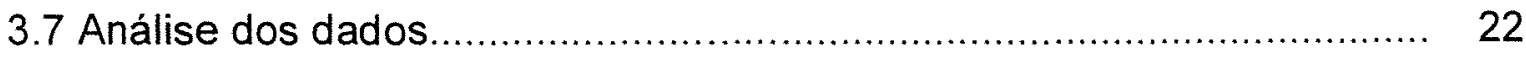

4 RESULTADOS E DISCUSSÅO...................................................... 24 
5 CONCLUSÕES

42

REFERÊNCIAS BIBLIOGRÁFICAS......................................... 43

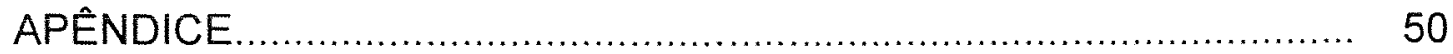




\section{LISTA DE TABELAS}

Página

1 Digestibilidade de diferentes gorduras em frangos de corte na primeira e segunda semanas de idade 5

2 Variação da digestibilidade de algumas fontes de gordura, conforme aumento de ácidos graxos livres (AGL) em relação aos triglicerídios (TG). 7

3 Digestibilidade (\%) e energia metabolizável (EM) de algumas fontes de gordura. 8

4 Valores de energia metabolizável (EM) determinados por diferentes pesquisadores variando o nivel de inclusão de sebo bovino na dieta e a idade das aves. 10

5 Composição das dietas basais.

6 Médias dos tratamentos para consumo de ração (CR), ganho de peso das aves (GP), conversão alimentar (CA) e viabilidade (VB) de1 a 7 dias de idade. .24

7 Contrastes e niveis de significância para cada variável, de 1 a 7 dias de idade. 
8 Médias dos tratamentos para consumo de ração (CR), ganho de peso das aves (GP), conversão alimentar (CA) e viabilidade (VB) de 1 a 14 dias de idade.

9 Contrastes e niveis de significância para cada variável de 1 a 14 dias de idade. 26

10 Médias dos tratamentos para consumo de ração (CR), ganho de peso das aves (GP), conversão alimentar (CA) e viabilidade (VB) de 1 a 21 dias de idade 27

11 Contrastes e niveis de significância para cada variável de 1 a 21 dias de idade.

12 Médias dos tratamentos para consumo de ração (CR), ganho de peso das aves (GP), conversão alimentar (CA) e viabilidade (VB) de 1 a 28 dias de idade. 30

13 Contrastes e niveis de significância para cada variável de 1 a 28 dias de idade 30

14 Médias dos tratamentos para consumo de ração (CR), ganho de peso das aves (GP), conversão alimentar (CA) e viabilidade (VB) de 1 a 35 dias de idade

15 Contrastes e niveis de significância para cada variável de 1 a 35 dias de idade. 
16 Médias dos tratamentos para consumo de ração $(C R)$, peso médio das aves (PM), ganho de peso das aves (GP), conversão alimentar (CA), viabilidade (VB) e fator de produção (FP) de 1 a 42 dias de idade.

17 Contrastes e niveis de significância para cada variável de 1 a 42 dias de idade. 32

18 Valores da gordura abdominal em $\%$ do peso vivo 37

19 Perfil de ácidos graxos das fontes de gordura, em \% ácidos graxos totais. 38

20 Perfil de ácidos graxos das gorduras abdominais, em $\%$ ácidos de graxos totais 39 


\title{
ÓlEO DE SOJA, ÓLEO ÁCIDO DE SOJA E SEBO BOVINO COMO FONTES DE GORDURA EM RAÇÕES PARA FRANGOS DE CORTE
}

\author{
Autor: JULIANO BENEDITO GAIOTTO \\ Orientador: Prof. Dr. JOSÉ FERNANDO MACHADO MENTEN
}

\section{RESUMO}

O experimento foi realizado do Departamento de Produção Animal da ESALQ - USP como intuito de avaliar o desempenho de frangos de corte suplementados com três fontes de gordura. Os tratamentos consistiam de rações à base de milho e farelo de soja, com adição total de $4 \%$ de gordura, proveniente de óleo ácido de soja (OAS4), sebo bovino (SEBO4), óleo de soja (SOJA4) e misturas de $2 \%$ cada fonte, compostas por óleo ácido de soja e sebo (OAS2/SEBO2), óleo ácido de soja e óleo de soja (OAS2/SOJA2) e óleo de soja e sebo bovino (SOJA2/SEBO2).

O delineamento experimental foi em blocos casualizados, com 6 tratamentos e 6 repetições, utilizando 40 aves por parcela, perfazendo um total de 1440 pintos machos de um de idade (AgRoss). Avaliaram-se os parâmetros 
de desempenho semanalmente: consumo de ração (CR), ganho de peso (GP), conversão alimentar (CA) e viabilidade (VB). Ao final do periodo experimental de 42 dias foram avaliados o peso vivo médio (PV) e o fator de produção (FP). Para análise dos resultados utilizou-se comparação de médias por contrastes:

1- SOJA4 X (OAS4 + SEBO4 + OAS2/SEBO2);

2- SOJA4 X (OAS2/SOJA2 + SOJA2/SEBO2);

3- OAS2/SOJA2 X SOJA2/SEBO2;

4- OAS4 X OAS2/SOJA2;

5- OAS 4 X OAS2/SEBO2.

No contraste 1 observou-se um menor $C R(P<0,06)$, melhor $C A(P<0,01)$, com superior GP $(P<0,01), P V(P<0,04)$ e FP $(P<0,01)$ para o tratamento SOJA4 em relação a média dos tratamentos OAS4, SEBO4 e OAS2/SEBO2, mostrando que a suplementação óleo de soja resultou em melhor desempenho quando comparado a das fontes alternativas de gordura. A comparação do tratamento SOJA4 com os tratamentos (OAS2/SOJA2 + SOJA2/SEBO2) realizada no contraste 2 não foi significativa para todas as variáveis $(P>0,10)$, mostrando melhorias no valor nutricional das fontes sebo bovino e óleo ácido de soja quando misturadas ao óleo de soja. O contraste 3 indicou que não houve diferença significativa entre os tratamentos OAS2/SOJA2 e SOJA2/SEBO2, exceto para VB $(P<0,02)$, confirmando que a mistura com óleo de soja melhorou igualmente a qualidade das fontes alternativas.

No contraste 4 a mistura OAS2/SOJA2 resultou num maior $\mathrm{GP}(\mathrm{P}<0,06)$, PV $(P<0,01)$ e FP $(P<0,01)$, com uma melhor conversão alimentar $(P<0,01)$ em relação ao OAS, o qual possui apenas ácidos graxos livres e não triglicerídios. Por outro lado, a mistura de sebo ao óleo ácido de soja (OAS2/SEBO2) não foi vantajosa em relação ao óleo ácido de soja para nenhuma das variáveis (contraste $5, P>0,10$ )

A quantidade de gordura abdominal não foi afeta pelos tratamentos, porém a composição de ácidos graxos das fontes refletiram na composição dos ácidos graxos das gorduras. $\mathrm{O}$ ácido graxo linoleico acumulou-se mais nas 
gorduras abdominais dos tratamentos OAS4, SOJA4, OAS2/SOJA2, SOJA2/SEBO2, enquanto que o ácido graxo oleico manteve sua composição próximas em todos os tratamentos com exceção dos maiores níveis no tratamento SOJA2/SEBO2.

O óleo de soja proporcionou melhor desempenho das aves, tanto em misturas 1:1 quanto com fonte única adicionadas a ração. $O$ óleo ácido de soja, o sebo e a mistura destes, resultaram em depressão do desempenho das aves. 


\title{
SOYBEAN OIL, ACIDULATED SOAPSTOCK BEEF TALLOW, AND MIXTURES OF FAT SOURCES IN BROILER DIETS
}

\author{
Author: JULIANO BENEDITO GAIOTTO \\ Adviser: JOSÉ FERNANDO MACHADO MENTEN
}

\section{SUMMARY}

Fats are commonly supplemented to broiler diets to increase the energy density of the feeds. Soybean oil is the standard source of fat and during periods of high prices of this ingredient, broiler producers are offered less expensive products. The alternative sources of fat are beef tallow, poultry oil, and acidulated soapstock, which may reduce bird performance because of less absorption, lower availability of energy, imbalance between saturated na unsaturated fatty acids or reduced bile secretion. The objective of this research was to evaluate the less expensive fat sources acidulated soapstock and beef tallow as an alternative to soybean oil in broiler diets. A total of 1,440 day-old male Ross chicks were raised to 42 days of age in floor pens in a radomized block design of six treatments and six replicates, and fed corn-soybean meal diets containing $4 \%$ of supplemental fat from the sources: soybean oil (SOY4), beef tallow (TAL4), acidulated soapstock (SOAP4), acidulated soapstock and tallow 1:1 (SOAP2/TAL2), acidulated soapstock and soybean oil (SOAP2/SOY2) and soybean oil and tallow 1:1 (SOY2/TAL2). Liveweight, weight gain, feed 
intake, daily feed intake, feed:gain ratio and mortality were recorded and results were statistically analysed using non-orthogonal contrasts:

1- SOY 4 X (SOAP4 + TAL4 + SOAP2/TAL2);

2- SOY $4 \times($ SOAP2/SOY2 + SOY $2 / T A L 2)$;

3- SOAP2/SOY $2 X$ SOY $2 / T A L 2$;

4- SOAP4 X SOAP2/SOY2;

5- SOAP4 X SOAP2/TAL2.

Liveweight, weight gain and feed:gain of SOY4 $(2.692 \mathrm{~kg}, 63 \mathrm{~g} / \mathrm{d}$ and 1.679 , respectively) were better $(P<.05)$ than those devoid of soybean oil in the diet $(2.650 \mathrm{~kg}, 61.7 \mathrm{~g} / \mathrm{d}$ and 1.731 , respectively), but feed intake $(4.513 \mathrm{~kg})$, daily feed intake $(107 \mathrm{~g} / \mathrm{d})$ and mortality $(1.87 \%)$ did not differ. On the other hand, the mixtures containing $2 \%$ soybean oil ( contrast 2 ) resulted in performance similar to SOY 4 in all variables $(P>.05)$ and the presence of soybean oil in the mixture equally improved the results of acidulated soapstock and tallow (liveweight 2.689 vs $2.687 \mathrm{~kg}$; weight gain 63 vs $63 \mathrm{~g} / \mathrm{d}$; feed gain 1.693 vs. 1.684 , respectively, contrast 3 ).

The performance of birds fed SOAP4 (liveweight $2.647 \mathrm{~kg}$, weight gain 62 $\mathrm{g} / \mathrm{d}$ and feed:gain 1.731) was inferior to those fed SOAP2/SOY2 $(P<.06)$ but was similar to those fed SOAP2/TAL2 $(2.663 \mathrm{~kg}, 62 \mathrm{~g} / \mathrm{d}$ and feed:gain 1.731, respectively).

The abdominal fat did not differ among the treatments, but abdominal fats reflected the composition of the different fats. Linoleic fatty acid increase to SOAP4, SOY4, SOAP2/SOY2, SOY $2 / T A L 2$ and oleic fatty acid increase to SOY2/TAL2.

These results confirmed the superiority of soybean oil relative to the other fat sources fed to broiler and demonstrated that the quality of acidulated sapstock and beef tallow may be improved when used in 1:1 mixtures with soybean oil. 


\section{INTRODUÇÃO}

O setor de carnes no Brasil passa por uma década de mudanças estruturais, seja por maior competitividade na economia aberta e estabilizada, ou reformas e tendências das políticas públicas. As novas tendências de mercado levaram ao achatamento das margens de lucro, obrigando a indústria avícola a reduzir os custos de produção.

Uma das alternativas para a redução de custos é a utilização de subprodutos da indústria alimentícia como fontes de nutrientes, como energia e proteina, nas rações de frangos de corte.

As rações de alto valor energético necessitam de adição de gordura para se atingir os níveis desejados de energia; entretanto, não há muitas opções de fontes de gordura no mercado, sendo a mais utilizada o óleo de soja, que onera substancialmente o custo das rações. Quando se utilizam outras fontes de gordura, como sebo bovino, óleo ácido de soja ou óleo de visceras de aves, o desempenho das aves pode ser reduzido por vários motivos: menor valor energético das fontes, redução da absorção de ácidos graxos e monoglicerídios, e problemas na excreção de bile. Essas fontes alternativas de energia têm preços mais baixos que o óleo de soja e seu uso nas rações pode representar economia, desde que o desempenho das aves não seja comprometido.

Além das fontes citadas, as misturas entre estas podem apresentar um potencial de utilização nas formulações de rações. O potencial apresentado pelas misturas não apenas se dá pelo desempenho e qualidade da carcaça, mas também pelas vantagens econômica apresentadas. Porém há necessidade 
de mais estudos para se determinar a energia metabolizável e avaliar as mudanças no desempenho e características da carcaça das aves alimentadas com diferentes proporções e tipos de gorduras.

O trabalho realizado procurou avaliar o desempenho de frangos de corte suplementados com três fontes de gordura adicionadas em $4 \%$ como fonte única ou em misturas duas a duas (2\%: $2 \%)$ a rações à base de milho e farelo de soja. A fonte de gordura utilizada como controle foi o óleo de soja, que possui valor energético conhecido e é rico em ácidos graxos insaturados. $O$ óleo ácido de soja foi utilizado como fonte de alternativa devido ao seu menor custo, quando comparado ao óleo de soja, e devido grande quantidade de ácidos graxos livres em sua composição. O sebo bovino foi adicionado como fonte de ácidos graxos saturados. A gordura abdominal foi determinada, assim com sua composição em ácidos graxos saturados. 


\section{REVISÃO DE LITERATURA}

\subsection{Utilização das gorduras}

A indústria avícola procura adaptar-se as novas tendências do mercado, tornando-se mais competitiva. Para isso há a necessidade de achatamento das margens de lucro e redução de custos (Jank, 1998).

Para haver uma efetiva redução do custos é necessário atacar os pontos que mais oneram a produção, que na avicultura industrial, mais especificamente na produção de frangos de corte, é a alimentação, que faz parte de aproximadamente $70 \%$ do custo de produção total. Dentro do custo de produção de rações, a energia é o item de maior custo; assim, utilizar matériasprimas de menor custo para a produção das rações, com o intuito de reduzir os custos finais de produção, é uma opção viável para obtenção maior competição no mercado.

Portanto fontes de gordura que apresentam menor custo, tornam-se viáveis para utilização, desde que não afetem o desempenho, o crescimento e a qualidade da carcaça dos animais (Arellano, 1992; Moran, 1994).

Além de sua importância como fonte concentrada de energia das rações, outras funções dos lipidios é facilitar a absorção dos pigmentos, aminoácidos e vitaminas lipossolúveis (Torres,1979; Rutz, 1994 e Firman et al., 1994).

Para se obter fontes de baixo custo há a necessidade da utilização de subprodutos da indústria alimentícia como fonte de lipídios. O óleo de soja é fonte de gordura mais utilizada na produção avicola. No entanto sua utilização 
fica inviável quando o óleo tem seu preço elevado, pois numa baixa de oferta nacional ou internacional de grãos de soja, elevam-se os preços e por conseqüência altera-se o preço do óleo de soja.

Uma segunda fonte utilizada pela indústria avícola é o óleo de visceras de aves, obtida do processamento das vísceras produzidas nos abatedouros avicolas, porém nem toda empresa possui um abatedouro ou produz esse produto suficientemente para atender sua demanda.

A utilização de outras fontes como o sebo bovino, o óleo ácido de soja, o óleo de palma, entre outros, é uma alternativa às fontes apresentada anteriormente, porém algumas fontes são de difícil obtenção e outras podem afetar o desempenho ou qualidade da carcaça produzida, sendo necessário um bom conhecimento das qualidades para usá-las de forma adequada.

\subsection{Digestão e absorção das gorduras}

A digestão dos lipídios no trato digestivo, mais especificamente no duodeno das aves, é realizada, principalmente pela lipase pancreática e sais biliares. Os sais biliares promovem a emulsificação das gorduras, para posterior ação da lipase pancreática nos triglicerídios, transformando-os em ácidos graxos livres e monoglicerídios. A lipase age nos ácidos graxos da posição 1 e 3 dos triglicerídios, projetados para fase aquosa do conteúdo intestinal, restando apenas o 2-monogliderídio nas gotículas de gordura. Tanto os sais biliares, quanto os 2-monoglicerídios são grandes agentes emulsificantes, capazes de formar espontaneamente, junto com ácidos graxos livres, as micelas de gordura. Logo após esta formação, as micelas migram para as vilosidades do intestino, onde sofrem uma desintegração e os ácidos graxos e monoglicerídos serão absorvidos (Garret \& Young, 1975; Sklan, 1979; Scott et al., 1982). 
Os elementos absorvidos serão ressintetizados na mucosa e combinarão com transportadores, que irão levá-los diretamente para o figado através da corrente sangüínea (Maynard, 1984; Krogdahl, 1985; Moran \& Vieira, 1996; Penz Jr \& Vieira, 1998).

\subsection{Absorção na fase inicial de desenvolvimento das aves}

Nos primeiros dias pós nascimento os pintos tem baixa capacidade de absorção de gordura Penz Jr. e Vieira (1998) não recomendam a utilização de lipidios na dieta pré-inicial de frangos de corte, pois a gordura não digerida no trato digestivo favoreceria a oxidação e sua excreção excessiva, além de reduzir a taxa de passagem e favorecer a utilização dessa energia por microrganismos prejudiciais ao desenvolvimento das aves.

Com o avanço da idade as aves aumentam a capacidade de absorção de gordura. Carew et al. (1972) mostraram que a digestibilidade do óleo de milho e sebo bovino aumentou gradativamente de 0 a 14 dias de idade (Tabela 1). Da mesma forma, Wiseman \& Salvador (1989) verificaram um aumento significativo na energia metabolizável aparente da gordura, em frangos de 10 a 25 dias, e aumentos menos pronunciados após este período.

Tabela 1: Digestibilidade de diferentes gorduras em frangos de corte na primeira e segunda semanas de idade.

\begin{tabular}{ccc}
\hline \multirow{2}{*}{$\begin{array}{c}\text { Idade } \\
\text { (semanas) }\end{array}$} & \multicolumn{2}{c}{ Digestibilidade $^{1}$} \\
\cline { 2 - 3 } & Óleo de milho & Sebo bovino \\
2 & $84 \mathrm{~b}$ & $40 \mathrm{~b}$ \\
\hline 1 & $95 \mathrm{a}$ & $78 \mathrm{a}$ \\
\hline
\end{tabular}

\footnotetext{
T- Letras diferentes na mesma coluna, indicam diferença $(P<0,02)$.

Fonte: Carew et al. (1972)
} 
A falha na absorção de gordura na fase inicial de desenvolvimento das aves pode ser explicada pela reduzida capacidade de produção de lipase pancreática e sais biliares na ave jovem. Noy \& Sklan (1995) quantificaram a secreção de lipase pancreática em frangos de corte de 4 a 21 dias de idade e observaram um aumento desta enzima à medida que as aves se desenvolveram neste periodo. Gomez \& Polin (1976) também estudaram o desenvolvimento inicial das aves medindo a absorção de gordura com a adição de ácidos biliares na dieta de aves de 0 a 21 dias; verificaram um aumento significativo da absorção de lipídios conforme aumentava a adição dos ácidos biliares. Com as novas linhagens de frangos de corte, as aves tornaram-se mais exigentes nas fase inicial de criação, necessitando de alimentos de alta qualidade que promovam o crescimento ideal dessas aves, porém há necessidade de desenvolver mais pesquisas referente ao uso de gordura na fase inicial de criação.

\subsection{Influência dos ácidos graxos livres na absorção de gorduras}

Todo processo descrito de digestão, absorção e ressintetização dos lipídios poderá ser prejudicado com a variação nos niveis de ácidos graxos livres das fontes de gordura. Algumas fontes tem como característica possuir elevados níveis de ácidos graxos livres, como é o caso das gorduras hidrolizadas e do óleo ácido de soja. Normalmente essas gorduras são subprodutos da indústria alimentícia, que acabam sofrendo uma ruptura da ligação dos triglicerídios em seu processamento, liberando glicerol e ácidos graxos.

A utilização dessas fontes de energia podem acarretar problemas de absorção pelas aves. A ação dos ácidos graxos livres ( $A G L$ ) influenciando na absorção dos lipídios foi descrita por Young (1961), que utilizou o óleo de milho como controle, uma mistura de óleo vegetal e gordura hidrolizada animal, 
contendo $40 \%$ de AGL e uma mistura de gordura hidrolizada animal mais óleo ácido de soja, contendo $95 \%$ de AGL. Este autor verificou que a digestibilidade do óleo de milho foi de $91,4 \%$, enquanto que a da mistura que continha $40 \%$ de AGL foi de $81,1 \%$, e a que continha $95 \%$ de $A G L$ foi de $69,6 \%$, na $4^{a}$ semana de idade das aves.

Da mesma forma, Wiseman \& Salvador (1991) utilizaram sebo bovino, óleo de palma e óleo de soja, misturados com seus óleos ácidos em diferentes proporções para obter vários niveis de AGL. Foi determinada a digestibilidade da gordura para os diferentes produtos, ocorrendo uma redução na digestibilidade da gordura à medida que aumentava os niveis de $A G L$ fornecidos na dieta das aves (Tabela 2).

Tabela 2: Variação da digestibilidade de algumas fontes de gordura, conforme aumento de ácidos graxos livres (AGL) em relação aos trigliceridios (TG).

\begin{tabular}{cccc}
\hline \multirow{2}{*}{ TG/AGL } & \multicolumn{3}{c}{ Digestibilidade } \\
\cline { 2 - 4 } & Sebo bovino & Óleo de palma & Óleo de soja \\
\hline $100: 0$ & 82 & 84 & 95 \\
$75: 25$ & 81 & 83 & 94 \\
$50: 50$ & 78 & 77 & 93 \\
$25: 75$ & 75 & 74 & 91 \\
$0: 100$ & 70 & 72 & 88 \\
\hline
\end{tabular}

Fonte: Wiseman \& Salvador (1991)

Posteriormente, Blanch et al. (1995), utilizando óleo de soja e misturas de 1:1 de sebo com óleo de soja ou com óleo ácido de soja, obtiveram maiores valores de digestibilidade e energia metabolizável para o óleo de soja e a mistura sebo e óleo de soja, ambos diferindo significativamente $(P<0,01)$ da mistura sebo e óleo ácido de soja (Tabela 3). 
Tabela 3: Digestibilidade (\%) e energia metabolizável (EM) de algumas fontes de gordura.

\begin{tabular}{lcc}
\hline \multicolumn{1}{c}{ Gordura } & Digestibilidade $(\%)^{1}$ & EM $(\mathrm{kcal} / \mathrm{kg})^{1}$ \\
\hline Óleo de soja & $94,03^{\mathrm{a}}$ & $8830^{\mathrm{a}}$ \\
Óleo de soja + sebo & $89,36^{\mathrm{a}}$ & $8363^{\mathrm{a}}$ \\
Óleo ácido de soja + sebo & $81,47^{\mathrm{b}}$ & $7540^{\mathrm{b}}$ \\
\hline
\end{tabular}

- Letras diferentes na mesma coluna diferem estatisticamente $(P<0,01)$.

Fonte: Blanch et al. (1995)

Confirmando os resultados apresentados anteriormente, Vila \& Garcia (1996) mostraram que a digestibilidade e a energia metabolizável reduzem com o aumento dos niveis de ácidos graxos livres na fontes de gordura.

Waldroup et al. (1995) utilizaram duas misturas de gordura animal e vegetal para obter diferentes níveis de $A G L, 29,8 \%$ e $44,7 \%$, porém não obtiveram diferenças significativas no desempenho das aves aos 42 dias de idade, provavelmente devido aos baixos niveis de AGL utilizados na dietas das aves.

2.5 Influência da proporção de ácidos insaturados e saturados na absorção de gorduras

Há constatações de que a proporção de ácidos graxos saturados e insaturados tem papel fundamental no processo de absorção de gorduras.

Segundo Renner \& Rill (1961) os ácidos graxos saturados palmítico e esteárico tiveram uma absorção de $30 \%$ e $20 \%$, respectivamente, quando se utilizou uma mistura que continha $50 \%$ de ácidos graxos insaturados. Quando 
se passou para $62 \%$ de ácidos graxos insaturados na mistura a absorção do palmítico e esteárico foi de $51 \%$ e $36 \%$, respectivamente. Com $76 \%$ de ácidos graxos insaturados a absorção foi de $84 \%$ e $78 \%$ para o palmítico e o esteárico, respectivamente.

Sibbald et al. (1961) misturaram $50 \%$ de óleo soja que continha $15 \%$ dos ácidos graxos palmítico e esteárico, $27,2 \%$ do ácido graxo oleico, $49,8 \%$ de linoleico e $7,5 \%$ de linolênico, com $50 \%$ de sebo bovino que continha $44 \%$ de ácidos graxos palmítico e esteárico, $41,5 \%$ de oleico, $7,5 \%$ de linoleico e $0,1 \%$ de linolênico e observaram o aumento da digestibilidade do sebo misturado em relação ao sebo como fonte única de gordura em rações de frangos.

Artman (1964) obteve diferenças significativas $(P<0,05)$ na digestibilidade do óleo de soja, quando comparado com óleo ácido de soja, sebo bovino e mistura de $1: 1$ entre sebo e óleo ácido de soja, adicionados $15 \%$ a ração das aves . A digestibilidade do óleo de soja foi de $95 \%$, enquanto a do óleo ácido foi de $86,2 \%$, do sebo, $68,2 \%$ e da mistura, $87 \%$.

Young \& Garrett (1963) mostraram que a mistura de fontes ricas em ácidos graxos palmítico $(P)$ e oleico $(O)$ aumentou em $10 \%$ a absorção de ácidos graxos saturados, quando a proporção O:P foi de 1,34:1 em comparação à proporção $0,8: 1$, concluindo que há uma facilitação da absorção de ácidos graxos saturados em presença de ácidos graxos insaturados.

A melhoria da absorção de ácidos graxos saturados obtida com as misturas de gordura explica a obtenção do efeito sinérgico, pois os valores obtidos de energia metabolizável são maiores que a média aritmética dos valores individuais dos componentes da mistura (Ketels \& De Groote, 1989; Zumbado et al., 1999). Os mecanismos que influenciam a maior absorção de ácidos graxos saturados e promovem o efeito sinérgico não foram ainda elucidados, mas uma das hipóteses é a adequação do perfil de ácidos graxos para melhor absorção. 


\subsection{Fatores que interferem na determinação da energia}

Vários fatores podem influenciar na determinação da energia da gordura, entre estes, o nivel de inclusão de gordura nas dietas, o tipo de dieta utilizada, ambiente, sexo, genética, sanidade, etc.

O nivel de inclusão de gorduras nas dietas pode influenciar de dois modos a determinação da energia. Primeiramente através do aumento da energia metabolizável, à medida que se suplementa mais gordura nas dietas (Young \& Artman, 1961). O aumento na digestibilidade e na energia metabolizável das gorduras à medida que se eleva o nível de inclusão de gordura na dieta também foi observado por Sibbald et al. (1961); Mateos \& Sell (1980); Mateos \& Sell (1981); Wiseman et al. (1986); Ketels \& De Groote (1988) e Wiseman \& Salvador (1989).

O segundo modo é o erro experimental, que é maior em rações que contém menor porcentagem de gordura substituída nas dietas. Sibbald \& Slinger (1963) mostraram que para cada $100 \mathrm{kcal} E M / \mathrm{kg}$ de erro na determinação de energia da dieta, resultará numa variação de $1000 \mathrm{kcal}$ EM/kg no valor atribuído a gordura, quando se utiliza apenas $10 \%$ desta na dieta. Utilizando-se $50 \%$ de gordura na dieta, a variação na energia desta será em torno de $200 \mathrm{kcal}$ EM/kg. Portanto, para se ter resultados confiáveis de determinação de EM, é necessário a substituição altos níveis de gordura na dieta experimental, sem que haja redução do consumo de ração pelas aves.

As variações de determinação influenciadas pelo tipo de dieta basal foram descritas por Sibbald \& Kramer (1980a), que utilizaram uma dieta a base de trigo e outra a base de milho suplementadas com $5 \%$ de sebo bovino e obtiveram $7390 \mathrm{kcal}$ EM/kg para o sebo bovino na dieta à base de trigo e 8740 kcal EM/kg para o sebo bovino na dieta a base de milho. Ainda Sibbald \& Kramer (1980b), agora utilizando 8 tipos de dietas basais para a determinação 
da energia metabolizável do sebo bovino, encontraram diferenças que variam de 7800 a $8260 \mathrm{kcal}$ EM/ kg de sebo bovino, adicionado em 4,5\% nas dietas.

Toda discussão anterior mostra a enorme variação na absorção da gorduras e na determinação da energia metabolizável, tornando difícil a comparação do valores determinados. Na tabela 4 estão apresentados os valores de energia metabolizável determinados por diferentes autores, conforme a idade e o nivel de inclusão de sebo bovino na dieta das aves.

Tabela 4: Valores de energia metabolizável (EM) determinados por diferentes pesquisadores variando o nível de inclusão de sebo bovino na dieta e a idade das aves.

\begin{tabular}{lccc}
\hline \multicolumn{1}{c}{ Autores } & $\begin{array}{c}\text { Idade } \\
\text { (semanas) }\end{array}$ & $\begin{array}{c}\text { Inclusão na dieta } \\
(\%)\end{array}$ & $\begin{array}{c}\text { EM } \\
(\mathrm{kcal} / \mathrm{kg})\end{array}$ \\
\hline Young et al. (1961) & $3-4$ & 15 & 6560 \\
Young et al. (1961) & $7-8$ & 15 & 6920 \\
Sibbald et al. (1961) & $2-3$ & 10 & 6400 \\
Sibbald et al. (1961) & $2-3$ & 20 & 7460 \\
Artman (1964) & $7-8$ & 15 & 7320 \\
NRC (1994) & - & 10 & $7268-7780^{1}$ \\
Rostagno et al (1996) & - & - & 7436 \\
\hline 1-Há vários outros valores atribuídos ao sebo dependendo de sua composição, nas tabelas do \\
NRC.
\end{tabular}

\subsection{Qualidade da carcaça das aves}

Além dos vários fatores que interferem na determinação da absorção e da EM das gorduras, necessita-se avaliar as alterações ocorridas nas características das carcaças das aves. Atualmente as pesquisas estão direcionadas a obter carcaças magras, com baixos niveis de acúmulo de 
gordura. Os principais fatores que influenciam o acúmulo de gordura nas carcaças das aves são o sexo, idade e energia fornecida através das rações.

Edwards Jr et al. (1973) mostraram que a gordura acumulada nas carcaças de machos e fêmeas aumenta com a idade e que nas fêmeas o acúmulo de gordura é maior do que nos machos na $4^{\mathrm{a}}$ e $5^{\mathrm{a}}$ semanas de vida.

Os resultados obtidos por Deaton \& Lott (1985) também mostraram que a gordura abdominal variou com a idade e o sexo das aves, pois durante 0 período de 36 a 54 semanas de idade esta aumentou $23 \%$ para os machos e $38 \%$ para as fêmeas, em porcentagem do peso corporal. Os mesmos autores observaram um aumento no acúmulo de gordura abdominal à medida que a energia passou de 3100 para $3325 \mathrm{kcal}$ EM/kg das dietas. Keren et al. (1990) também obtiveram maior acúmulo de gordura abdominal com a elevação da energia da dieta.

Além dos fatores que interferem na quantidade de gordura acumulada na carcaça, Edwards Jr et al. (1973) determinaram a influência da alimentação de vários tipos de gordura, entre elas, o sebo bovino e o óleo de vísceras de aves, na composição de ácidos graxos da carcaça e gordura abdominal. Apesar do tipo de gordura utilizado na dieta não ter influenciado a composição corporal das aves, alterou a composição dos ácidos graxos da carcaça e da gordura abdominal. A alimentação com sebo bovino elevou o conteúdo de ácidos graxos esteárico e oleico do tecido adiposo, enquanto que o óleo de vísceras de aves reduziu o ácido graxo linoleico e aumentou o oleico da gordura abdominal.

Yau et al. (1991) utilizaram óleo de coco com $83 \%$ de ácidos graxos saturados, óleo de girassol com $79 \%$ de ácidos graxos linoleico e óleo de oliva com $70 \%$ de ácidos graxos oleico, adicionados em $8 \%$ na dietas de frangos de corte, e observaram um aumento mais pronunciado destes ácidos graxos na gordura abdominal que gordura intramuscular. Entretanto, em ambas as porcentagens de proteína, lipídios e matéria seca não sofreram alterações.

Zollitsch et al. (1996) utilizaram várias fontes de gordura suplementadas as dietas de frangos de corte para avaliar as alterações ocorridas nas carcaças. 
As fontes utilizadas foram o óleo de soja, o óleo de colza e duas misturas de óleos, sendo que uma continha elevados níveis de ácidos graxos insaturados, e a outra possuia mais ácidos graxos saturados. Todas as fontes foram adicionadas em $3,5 \%$ às dietas. Não houve diferença significativa no conteúdo de gordura, proteína e matéria seca da coxa e do peito das aves. A composição de ácidos graxos da gordura abdominal foi influenciada pelas fontes de gordura, pois no caso do óleo de soja o conteúdo de ácidos graxos insaturados foi maior em relação às outras fontes, assim como a mistura de gordura rica em ácidos graxos saturados resultou em maior concentração destes na gordura abdominal das aves.

Sanz et al. (1999) utilizaram sebo bovino, banha suína e óleo de soja adicionados em $8 \%$ nas dietas de frangos de corte e avaliaram as alterações ocorridas na carcaças. A composição de ácidos graxos foi alterada na gordura abdominal e na gordura intramuscular neutra, que corresponde os trigliceridios acumulados no tecido muscular. Já a gordura a gordura intramuscular polar, que correspondem aos fosfolipidios formadores das membranas das células, não sofreram ação significativa com o fornecimento de diferentes fontes de gordura nas dietas, provavelmente porque alterações nas membranas trariam problemas fisiológicos às células.

Outros autores (Olomu \& Baracos, 1991; Hrdinka et al., 1996 e Peebles et al., 1997) obtiveram resultados semelhantes no que diz respeito a alteração da composição de ácidos graxos nas gorduras abdominal e intramuscular.

Portanto as alterações ocorridas na gordura abdominal, assim como na intramuscular poderiam alterar o ponto de fusão, com conseqüências na consistência da gordura. Neste caso, os ácidos graxos saturados, que possuem maior ponto de fusão, quando presente nas gorduras, podem deixá-las mais sólidas. Inversamente, a presença de ácidos graxos insaturados nas gorduras deixam-nas menos sólidas e susceptiveis a oxidação, o que resultaria em problemas de processamento e conservação desses produtos. 


\section{MATERIAL E MÉTODOS}

\subsection{Local}

O experimento foi realizado no aviário experimental do Departamento de Produção Animal da Escola Superior de Agricultura "Luiz de Queiroz", localizado no município de Piracicaba, SP.

\subsection{Instalações e Metodologia Experimental}

O galpão experimental tem comprimento de $32 \mathrm{~m}$ por $8 \mathrm{~m}$ de largura e pédireito de $3 \mathrm{~m}$. Possui uma mureta lateral de $0,6 \mathrm{~m}$, piso de concreto, lanternim e telhados cobertos com telha de barro, equipado com cortinas e tela até o teto. Há duas portas, sendo que uma dá acesso ao corredor central e a outra a área de serviço de $28 \mathrm{~m}^{2}$, utilizada para armazenamento das rações. O galpão possui 36 boxes experimentais dispostos em duas fileiras longitudinais com 18 boxes cada, separadas por um corredor central de $2 \mathrm{~m}$ de largura. Cada box possui uma área de $4,5 \mathrm{~m}^{2}$ e uma porta de acesso ao corredor central.

Para cada box foram utilizados uma lâmpada de aquecimento, mantida até $\circ 14^{\circ}$ dia de experimentação, um comedouro de $5 \mathrm{~kg}$ de capacidade, utilizado até $014^{\circ}$ dia de idade, um bebedouro para pintos, que foi mantido até o $5^{\circ}$ dia de experimentação, além de duas placas de eucatex, que formavam 
um círculo para reduzir a área de movimentação das aves e prover um melhor controle da temperatura ambiente, sendo mantidas até o $14^{\circ}$ dia de idade.

No $6^{\circ}$ dia de idade os bebedouros de pintos foram substituidos por bebedouros pendulares, assim como no $14^{\circ}$ dia foram substituídos os comedouros de $5 \mathrm{~kg}$ pelos de $25 \mathrm{~kg}$ de capacidade.

Foram utilizadas duas balanças para as pesagens semanais das rações e aves. Dois termômetros dispostos, um em cada fileira de boxes, foram utilizados para registrar a temperatura máxima e mínima, às 9 horas da manhã, durante todo periodo experimental.

Foi utilizado como cama para as aves uma mistura de maravalha de madeira e casca de arroz, espalhados homogeneamente por todo box.

No primeiro dia de experimentação, logo após a chegada dos pintos, confirmou-se a sexagem, estado fisico e a sanidade do lote. Em seguida as aves foram pesadas, divididas em sublotes de 40 aves e distribuídas no boxes de forma homogênea conforme seu peso. O peso médio inicial das aves foi de $43,5 \mathrm{~g}$. Água e ração foram fornecidas à vontade durante todo período experimental.

$\mathrm{Na}$ segunda semana as aves foram vacinadas contra as doenças de Gumboro e Newcastle, administrada via oral na água de bebida.

Tanto as aves como as rações foram pesadas semanalmente até os 42 dias de idade. A mortalidade foi registrada diariamente e as aves mortas foram pesadas para correção da conversão alimentar e do consumo de ração

Aos 42 dias de idade foi selecionada uma ave por parcela, com peso próximo ao peso médio do box, que foi abatida e retirados a gordura abdominal.

Para análise do perfil de ácidos graxos foram utilizadas $20 \mathrm{~g}$ de gordura abdominal de cada ave abatida. As amostras foram reunidas dentro dos tratamentos e colocadas em banho maria até a separação total entre a gordura e os tecidos. Controlou-se a temperatura (aproximadamente $60^{\circ} \mathrm{C}$ ) para que não houvesse perdas de ácidos graxos. Após a extração, a gordura foi 
acondicionada em frascos de vidro e levada ao freezer, para posterior envio ao laboratório de análises.

\subsection{Rações}

O programa de alimentação do periodo experimental foi dividido em três fases, a fim de atender as exigência de cada fase de desenvolvimento das aves. As dietas foram formuladas à base de milho e farelo de soja, para atender os níveis nutricionais de aminoácidos, cálcio e fósforo propostos por Rostagno (1996) (Tabela 5).

As fases de criação foram:

- $1^{a}$ fase: ração inicial - do $1^{\circ}$ ao $21^{\circ}$ dia de idade;

- $2^{a}$ fase: ração crescimento - do $22^{\circ}$ ao $35^{\circ}$ dia de idade;

- $3^{\text {a }}$ fase: ração final - do $36^{\circ}$ ao $42^{\circ}$ dia de idade.

A energia metabolizável utilizada na fase inicial foi de $3051 \mathrm{kcal} \mathrm{EM} / \mathrm{kg}$ e $22,5 \%$ de $\mathrm{PB}$, para a fase de crescimento utilizou-se $3109 \mathrm{kcal}$ EM/kg e 20,5\% de PB e para fase final $3158 \mathrm{kcal}$ EM/kg e $19,0 \%$ de PB.

O óleo de soja foi utilizado como gordura padrão para a formulação da dieta basal, adicionado no total de $4 \%$. A partir desta dieta, o óleo de soja foi substituído pelas outras gorduras. 
Tabela 5 - Composição das dietas basais.

\begin{tabular}{|c|c|c|c|}
\hline INGREDIENTES & $1^{2}$ FASE & $2^{a}$ FASE & $3^{a}$ FASE \\
\hline MILHO & 52,635 & 57,935 & 62,081 \\
\hline FARELO DE SOJA & 39,519 & 34,150 & 30,081 \\
\hline ÓLEO DE SOJA & 4,000 & 4,000 & 4,000 \\
\hline CALCARIO CALCITICO & 1,100 & 1,093 & 1,279 \\
\hline FOSFATO BICÁLCICO & 1,947 & 2,040 & 1,797 \\
\hline DL-METIONINA & 0,057 & 0,051 & 0,040 \\
\hline SAL & 0,300 & 0,300 & 0,300 \\
\hline SUPL. VITAM. E MINERAL & $0,300^{1}$ & $0,300^{2}$ & $0,300^{2}$ \\
\hline CLORETO-COLINA $60 \%^{3}$ & 0,030 & 0,020 & 0,010 \\
\hline SUPLEMENTO ADITIVOS & $0,100^{4}$ & $0,100^{5}$ & $0,100^{5}$ \\
\hline ANTIOXIDANTE ${ }^{6}$ & 0,012 & 0,012 & 0,012 \\
\hline
\end{tabular}

\section{NIVEIS CALCULADOS}

\begin{tabular}{lccc}
\hline NUTRIENTES & $\mathbf{1}^{\text {a }}$ FASE & $\mathbf{2}^{\text {a }}$ FASE & $\mathbf{3}^{\text {a }}$ FASE \\
\hline EM (kcal/kg) & 3051 & 3109 & 3158 \\
PB (\%) & 22,5 & 20,5 & 19,0 \\
Gordura (\%) & 6,03 & 6,17 & 6,27 \\
Metionina (\%) & 0,47 & 0,45 & 0,40 \\
Met. + cist. (\%) & 0,90 & 0,86 & 0,78 \\
Lisina (\%) & 1,18 & 1,11 & 1,00 \\
Triptofano (\%) & 0,30 & 0,27 & 0,25 \\
Treonina (\%) & 0,88 & 0,80 & 0,74 \\
Fósf. dispon. (\%) & 0,45 & 0,46 & 0,41 \\
Cálcio (\%) & 1,00 & 1,00 & 1,00 \\
\hline
\end{tabular}

1-Concentração por $\mathrm{kg}$ de produto: vit. A $2.250 .000 \mathrm{UI}$; vit. $\mathrm{D}_{3} 450.000 \mathrm{Ul}$; vit. E $5,25 \mathrm{~g}$; vit. $\mathrm{K} 0,36 \mathrm{~g}$; vit. $B_{2} 1,13 \mathrm{~g}$; vit. $B_{12} 3,75 \mathrm{mg}$; pantotenato de $C a 2,58 \mathrm{~g}$; metionina $325 \mathrm{~g}$; niacina $7,46 \mathrm{~g}$; colina $62,25 \mathrm{~g}$; selênio $52 \mathrm{mg}$; Antioxidante $1,25 \mathrm{~g}$, manganês $14,5 \mathrm{~g}$; cobre $12,5 \mathrm{~g}$; zinco $12,5 \mathrm{~g}$; ferro $14 \mathrm{~g}$; iodo $0,15 \mathrm{~g}$; cobalto $21 \mathrm{mg}$.

2-Concentração por $\mathrm{kg}$ de produto: vit. A $1.875 .000 \mathrm{Ul}$; vit. $\mathrm{D}_{3} 375.000 \mathrm{Ul}$; vit. E $3,25 \mathrm{~g}$; vit. $\mathrm{K} 0,27 \mathrm{~g}$; vit. $B_{2} 0,90 \mathrm{~g}$; vit. $B_{12} 2,5 \mathrm{mg}$; pantotenato de $C a 1,99 \mathrm{~g}$; metionina $300 \mathrm{~g}$; niacina $6,27 \mathrm{~g}$; colina $48,8 \mathrm{~g}$; selênio $43 \mathrm{mg}$; antioxidante $1,28 \mathrm{~g}$, manganês $14,5 \mathrm{~g}$; cobre $1,75 \mathrm{~g}$; zinco $12,5 \mathrm{~g}$; ferro $14 \mathrm{~g}$; iodo $0,15 \mathrm{~g}$; cobalto $21 \mathrm{mg}$.

$3-52 \%$ de colina.

4-Nicarbazina $50 \mathrm{mg} / \mathrm{kg}$; avilamicina $6 \mathrm{mg} / \mathrm{kg}$; olaquindox $50 \mathrm{mg} / \mathrm{kg}$.

5-Avilamicina $5 \mathrm{mg} / \mathrm{kg}$; olaquindox $40 \mathrm{mg} / \mathrm{kg}$; ácido 3-nitro $30 \mathrm{mg} / \mathrm{kg}$; monensina sódica $110 \mathrm{mg} / \mathrm{kg}$.

6 -Etoxiquim. 


\subsection{Fontes de gordura utilizadas}

Foram utilizadas as gorduras óleo de soja, óleo ácido de soja e sebo bovino, que apresentam composições e propriedades distintas, como suplemento energético às rações das aves. $O$ óleo de soja foi usado como uma fonte padrão de gordura, considerada de boa qualidade e rica em triglicerídios e ácidos graxos insaturados.

Uma das fontes alternativas utilizadas como fonte de gordura foi o óleo ácido de soja, eventualmente também chamado de "ácido graxo de soja" ou "borra acidulada". Esta gordura é um subproduto obtido a partir da chamada "borra" (soapstock), a qual é resíduo do refino do óleo de soja bruto. O processo de obtenção do óleo ácido de soja a partir da borra se dá através da adição de ácido sulfúrico, processo chamado de acidificação, e posterior decantação da parte sólida, sendo o sobrenadante o óleo ácido de soja.

O sebo bovino foi utilizado como fonte de gordura animal, contendo elevada quantidade de ácidos graxos saturados.

As análises de controle de qualidade, da fontes de gordura utilizadas no experimento, foram realizadas na Nutron Alimentos Ltda, em Campinas, SP e se encontram no Apêndice 6. 


\subsection{Delineamento Experimental e Tratamentos}

O delineamento experimental foi em blocos casualizados, devido a variação ambiental dentro do galpão detectada em experimentos anteriores, com 6 tratamentos e 6 blocos. Foram utilizados 40 aves por box, num total de 36 boxes.

Tratamentos utilizados:

- SOJA4 = dieta basal (suplementação de $4 \%$ de óleo de soja).

- OAS4 = dieta basal, com substituição do óleo de soja por $4 \%$ de óleo ácido de soja.

- SEBO4 = dieta basal, com substituição do óleo de soja por $4 \%$ de sebo bovino.

- OAS2/SEBO2 = dieta basal, com substituição do óleo de soja por $2 \%$ de óleo ácido de soja e $2 \%$ de sebo bovino;

- OAS2/SOJA2 = dieta basal, com substituição do óleo de soja por $2 \%$ de óleo ácido de soja e $2 \%$ de óleo de soja.

- SOJA2/SEBO2 = dieta basal, com substituição do óleo de soja por $2 \%$ de óleo de soja e $2 \%$ de sebo bovino.

\subsection{Variáveis Dependentes}

As variáveis dependentes analisadas cumulativamente, semana a semana, até os 42 dias de idade foram:

- Ganho de peso das aves (GP)

O ganho de peso das aves, em $\mathrm{kg}$, foi obtido subtraindo-se do peso vivo médio o peso médio inicial das aves. 
- Conversão alimentar (CA)

Obtida dividindo-se o consumo de ração pelo ganho de peso das aves e corrigida, pela fórmula abaixo, no caso em que ocorreu morte das aves.

$$
\mathrm{CA}=\frac{\text { Consumo de ração }}{\text { Peso total das aves vivas }+ \text { peso total das aves mortas }}
$$

- Consumo de ração (CR)

O consumo de ração por ave foi determinado em $\mathrm{kg}$, pela diferença entre a ração fornecida, menos a sobra da ração, pesada semanalmente, em cada parcela, dividido pelo número de aves da mesma. Nos casos em que ocorreu morte de aves o consumo foi corrigido pela fórmula:

$\mathrm{CR}=\mathrm{CA}$ corrigida $\times$ ganho de peso

- Viabilidade (VB)

A viabilidade foi calculada como a proporção de aves vivas em cada box, expressa em \%

As variáveis dependentes analisadas apenas aos 42 dias de idade, além da citadas anteriormente, foram:

- Peso vivo das aves (PV)

Obtido dividindo-se o peso total da parcela, em $\mathrm{kg}$, pelo número de aves pesadas na semana 
- Fator de produção (FP)

Esta variável é utilizada no campo para se determinar a eficiência do lote para que seja feita a remuneração do criador. Assim esse índice pode sofrer algumas alterações de empresa para empresa.

O fator de produção foi calculado pela fórmula:

$$
F P=\frac{V B(\%) \times G D P(k g)}{C A} \times 100
$$

Onde o ganho diário de peso (GDP) é obtido dividindo de ganho de peso pelo número de dias do periodo, neste caso 42 dias.

- Peso da gordura abdominal (PG)

O peso da gordura abdominal foi expresso em \% do peso vivo da ave amostrada.

$$
P G=\frac{\text { peso da gordura abdominal em } \mathrm{kg}}{\text { peso vivo da ave em } \mathrm{kg}} \times 100
$$

Análises laboratoriais:

- Perfil de ácidos graxos da gordura abdominal e fontes de gordura.

As análises de perfil de ácidos graxos foram realizadas na Fundação do Instituto de Pesca do Estado do Rio de Janeiro (FIPERJ), através da técnica de cromatografia gasosa. 


\subsection{Análise dos dados}

Os resultados de desempenho dos animais foram submetidas a análise estatística usando-se Proc GLM do Programa SAS - Statistical Analyses System (SAS Institute, 1989) e as comparações de médias feitas através de contrates não ortogonais, utilizando o modelo matemático referente a blocos casualizados, mostrado a seguir:

$$
y_{i j}=\mu+t_{i}+b_{j}+E_{i j}
$$

$y_{i j}=$ resposta observada do i-ésimo tratamento no j-ésimo bloco;

$\mu=$ é uma constante;

$t_{i}=$ é o efeito do i-ésimo tratamento na variável dependente;

$\mathbf{b}_{\mathbf{j}}=$ é o efeito do j-ésimo bloco na variável dependente;

$E_{i j}=$ é o erro aleatório atribuído à observação dependente.

Partindo dos resultados obtidos nos experimentos da literatura, os contraste planejados compararam a gordura padrão, neste caso o óleo de soja, com os tratamentos que não continham o óleo de soja (contraste1), para comprovar se este resultaria em melhor desempenho. No contraste 2 comparou-se óleo de soja como fonte única de gordura e as misturas contendo óleo de soja e as fontes alternativas, óleo ácido de soja e sebo bovino, para verificar se as misturas eram equivalentes ao óleo de soja isoladamente. No contraste 3 houve um desmembramento da mistura que continha óleo de soja, para se verificar se as fontes alternativas misturadas a este, poderiam alterá-lo.

No contrate 4 comparou-se o óleo ácido de soja com a mistura óleo de soja e óleo ácido de soja para verificar as alterações no desempenho das aves, caso fosse adicionada a gordura padrão na fonte alternativa. 
No contrate 5 comparou-se o óleo ácido de soja com a mistura óleo ácido de soja e sebo bovino, a fim de verificar possiveis diferenças de desempenho das aves com a adição de sebo bovino, que é rico em ácidos graxos saturados.

As análises de desempenho das aves foram realizadas semanalmente, utilizando comparação das médias por contraste à saber:

- Contraste 1:- SOJA4 X (OAS4 + SEBO4 + OAS2/SEBO2);

- Contraste 2:- SOJA4 X (OAS2/SOJA2 + SOJA2/SEBO2);

- Contraste 3:- OAS2/SOJA2 X SOJA2/SEBO2;

- Contraste 4:- OAS4 X OAS2/SOJA2;

- Contraste 5:- OAS4 X OAS2/SEBO2. 


\section{RESULTADOS E DISCUSSÃO}

Os resultados de desempenho obtidos de 1 a 7 dias de idade são apresentados na Tabela 6 e a análise dos contrates na Tabela 7. O único contraste a apresentar significância estatística foi o contraste 1 . Neste contraste, o tratamento SOJA4 resultou em melhor conversão alimentar que a média dos tratamentos OAS4, SEBO4 e OAS2/SEBO2 $(1,27$ vs $1,33, \mathrm{P}<0,06)$.

Os dados coletados durante o periodo experimental, por parcela, estão apresentados nos Apêndices 1 a 5 .

Tabela 6: Médias dos tratamentos para consumo de ração (CR), ganho de peso (GP), conversão alimentar (CA) e viabilidade (VB) de1 a 7 dias de idade.

\begin{tabular}{lcccc}
\hline Tratamentos & CR $(\mathrm{kg})$ & GP $(\mathrm{kg})$ & CA & VB $(\%)$ \\
\hline OAS4 & 0,146 & 0,110 & 1,32 & 100,0 \\
SEBO4 & 0,150 & 0,113 & 1,32 & 100,0 \\
SOJA4 & 0,144 & 0,113 & 1,27 & 100,0 \\
OAS2/SEBO2 & 0,148 & 0,110 & 1,34 & 100,0 \\
OAS2/SOJA2 & 0,142 & 0,112 & 1,26 & 100,0 \\
SOJA2/SEBO2 & 0,146 & 0,113 & 1,29 & 100,0 \\
\hline C.V.(\%) & 5,14 & 2,27 & 4,76 & -
\end{tabular}

C.V (\%) - coeficiente de variação 
Tabela 7 : Contrastes e níveis de significância para cada variável, de 1 a 7 dias de idade.

\begin{tabular}{ccccc}
\hline Contrastes & CR $(\mathrm{kg})$ & GP $(\mathrm{kg})$ & $\mathrm{CA}$ & VB (\%) \\
\hline 1 & n.s. & n.s. & $\mathrm{P}<0,06$ & - \\
2 & n.s. & n.s. & n.s. & - \\
3 & n.s. & n.s. & n.s. & - \\
4 & n.s. & n.s. & n.s. & - \\
5 & n.s. & n.s. & n.s. & - \\
\hline
\end{tabular}

Os resultados de desempenho obtidos de 1 a 14 dias de idade são apresentados na Tabela 8 e a análise dos contrates na Tabela 9 . No contraste 1 o tratamento SOJA4 apresentou um consumo de ração $3,5 \%$ menor que a média dos tratamentos OAS4, SEBO4, OAS2/SEBO2 $(0,463$ vs $0,480 \mathrm{~kg}$, $P<0,02)$, acompanhada de uma melhor conversão alimentar $(1,32$ vs 1,39 , $P<0,01)$.

A variável ganho de peso do contraste 4 apresentou uma superioridade de $3,5 \%$ do tratamento OAS2/SOJA2 em relação ao OAS4 $(0,353$ vs $0,340 \mathrm{~kg}$, $P<0,04)$, acompanhada de uma melhor conversão alimentar $(1,35$ vs 1,41 , $P<0,01)$.

A conversão alimentar foi melhor para o tratamento OAS2/SEBO2 em relação ao tratamento OAS4 no contraste $5(1,36$ vs $1,41, P<0,05)$. 
Tabela 8 : Médias dos tratamentos para consumo de ração (CR), ganho de peso das aves (GP), conversão alimentar (CA) e viabilidade (VB) de 1 a 14 dias de idade.

\begin{tabular}{lcccc}
\hline Tratamentos & CR $(\mathrm{kg})$ & GP $(\mathrm{kg})$ & CA & VB $(\%)$ \\
\hline OAS4 & 0,480 & 0,340 & 1,41 & 99,5 \\
SEBO4 & 0,486 & 0,344 & 1,41 & 99,5 \\
SOJA4 & 0,463 & 0,349 & 1,32 & 100,0 \\
OAS2/SEBO2 & 0,474 & 0,346 & 1,36 & 99,1 \\
OAS2/SOJA2 & 0,477 & 0,353 & 1,35 & 99,5 \\
SOJA2/SEBO2 & 0,472 & 0,355 & 1,33 & 98,3 \\
\hline C.V.(\%) & 3,00 & 2,79 & 2,37 & 1,18 \\
\hline C.V $(\%)-$ coeficiente de variação & & &
\end{tabular}

Tabela 9 : Contrastes e niveis de significância para cada variável de 1 a 14 dias de idade.

\begin{tabular}{ccccc}
\hline Contrastes & CR $(\mathrm{kg})$ & GP $(\mathrm{kg})$ & $\mathrm{CA}$ & $\mathrm{VB}(\%)$ \\
\hline 1 & $\mathrm{P}<0,02$ & n.s. & $\mathrm{P}<0,01$ & n.s. \\
2 & n.s. & n.s. & n.s. & n.s. \\
3 & n.s. & n.s. & n.s. & n.s. \\
4 & n.s. & $\mathrm{P}<0,04$ & $\mathrm{P}<0,01$ & n.s. \\
5 & n.s. & n.s. & $\mathrm{P}<0,05$ & n.s. \\
\hline
\end{tabular}

Os resultados de desempenho obtidos de 1 a 21 dias de idade são apresentados na Tabela 10 e a análise dos contrates na Tabela 11. No contraste 1 o tratamento SOJA4 apresentou um ganho de peso $3,0 \%$ superior a média dos tratamentos OAS4, SEBO4, OAS2/SEBO2 (0,732 vs $0,709 \mathrm{~kg}$, $P<0,01)$, acompanhada de uma melhor conversão alimentar $(1,39$ vs 1,45 , $P<0,01)$.

A variável ganho de peso do contraste 4 apresentou uma superioridade de $3,7 \%$ do tratamento OAS2/SOJA2 em relação ao OAS4 $(0,727$ vs $0,700 \mathrm{~kg}$, 
$P<0,01)$, acompanhada de uma melhor conversão alimentar $(1,42$ vs 1,47 , $\mathrm{P}<0,01)$.

No contraste 2 a viabilidade foi superior $1,5 \%$ no tratamento SOJA4 em relação aos tratamentos OAS2/SOJA2 e SOJA2/SEBO2 (99,5 vs 98,0\%, $P<0,02)$. No contraste 3 a viabilidade foi superior $2,1 \%$ no tratamento OAS2/SOJA2 em relação ao tratamento SOJA2/SEBO2 (99,1 vs $97,0 \%$, $P<0,01)$.

Tabela 10 : Médias dos tratamentos para consumo de ração $(\mathrm{CR})$, ganho de peso das aves (GP), conversão alimentar (CA) e viabilidade (VB) de 1 a 21 dias de idade.

\begin{tabular}{lcccc}
\hline Tratamentos & CR $(\mathrm{kg})$ & GP $(\mathrm{kg})$ & CA & VB (\%) \\
\hline OAS4 & 1,031 & 0,700 & 1,47 & 99,5 \\
SEBO4 & 1,046 & 0,713 & 1,46 & 99,5 \\
SOJA4 & 1,019 & 0,732 & 1,39 & 99,5 \\
OAS2/SEBO2 & 1,023 & 0,715 & 1,43 & 99,1 \\
OAS2/SOJA2 & 1,033 & 0,727 & 1,42 & 99,1 \\
SOJA2/SEBO2 & 1,027 & 0,725 & 1,41 & 97,0 \\
\hline C.V.(\%) & 3,15 & 2,53 & 2,07 & 1,21 \\
\hline C.V $(\%)-$ coeficiente de variação & & &
\end{tabular}

Tabela 11: Contrastes e niveis de significância para cada variável de 1 a 21 dias de idade.

\begin{tabular}{ccccc}
\hline Contrastes & CR $(\mathrm{kg})$ & GP $(\mathrm{kg})$ & $\mathrm{CA}$ & $\mathrm{VB}(\%)$ \\
\hline 1 & n.s. & $\mathrm{P}<0,01$ & $\mathrm{P}<0,01$ & n.s. \\
2 & n.s. & n.s. & n.s. & $\mathrm{P}<0,02$ \\
3 & n.s. & n.s. & n.s. & $\mathrm{P}<0,01$ \\
4 & n.s. & $\mathrm{P}<0,01$ & $\mathrm{P}<0,01$ & n.s. \\
5 & n.s. & n.s. & n.s. & n.s. \\
\hline
\end{tabular}


O tratamento SOJA4 apresentou uma conversão alimentar melhor, ora acompanhada de menor consumo de ração, ora acompanhada de maior ganho de peso, quando comparado com a média dos tratamentos OAS4, SEBO4 e OAS2/SEBO2, já a partir da primeira semana. A superioridade do desempenho das aves recebendo óleo de soja em comparação aos tratamentos isentos deste, fica evidente no contraste 1. A comparação entre o tratamento SOJA4 e as misturas OAS2/SOJA2 e SOJA2/SEBO2, assim como a comparação entre essas misturas, realizadas nos contrastes 2 e 3 , respectivamente, mostram que não houve diferença de desempenho quando o óleo de soja estava isoladamente ou em misturas nas rações. No contraste 4 ratifica-se a superioridade de desempenho do tratamento OAS2/SOJA2 em relação ao OAS4.

A utilização de gordura nas primeiras semanas de criação das aves não é uma prática usual de alguns empresas avicolas, que temem possiveis problemas de absorção, pois alguns pesquisadores mostram a baixa capacidade absortiva da aves nas primeiras semanas de vida. Carew Jr et al. (1972) mostraram que a digestibilidade do óleo de milho foi de $84 \%$, quando comparada com sebo bovino que apresentou $40 \%$ de digestibilidade na primeira semana de idade. Na segunda semana a digestibilidade do óleo de milho foi de $95 \%$ e a do sebo bovino de $79 \%$, mostrando que a absorção de gordura pode variar não apenas com o tipo de gordura fornecida, mas também conforme a idade, principalmente na fase inicial de criação das aves.

Da mesma forma, Wiseman \& Salvador (1989) obtiveram maiores valores de digestibilidade e energia metabolizável aparente para uma mistura de óleos vegetais, em relação ao sebo bovino em frangos de 10 a 25 dias de idade e aumentos menos pronunciados após este período.

O processo de menor absorção de gordura na fase inicial de desenvolvimento das aves, pode ser explicado pela reduzida capacidade de produção de lipase pancreática e sais biliares. Noy \& Sklan (1995) quantificaram a secreção de lipase pancreática em frangos de corte de 4 a 21 
dias de idade e observaram um aumento desta enzima à medida que as aves se desenvolveram.

Gomez \& Polin (1976) também estudando o desenvolvimento inicial das aves, mas medindo a absorção de gordura com a adição de ácidos biliares na dieta de aves de 0 a 21 dias, observaram um aumento significativo da absorção de lipídios conforme aumentava a adição dos ácidos biliares.

Há muitas dúvidas e contradições no que diz respeito ao uso de gordura na fase inicial de criação. Os resultados obtidos neste trabalho, comparado aos encontrados na literatura, por si só, demostram a necessidade de mais estudos envolvendo o uso de gordura nas primeiras semanas de vida das aves.

Os resultados de desempenho obtidos de 1 a 28 dias de idade são apresentados na Tabela 12 e a análise dos contrates na Tabela 13. No contraste 1 o tratamento SOJA4 apresentou um consumo de ração 1,8\% inferior a média dos tratamentos OAS4, SEBO4, OAS2/SEBO2 (1,900 vs $1,934 \mathrm{~kg}$, $P<0,08)$, acompanhada de uma melhor conversão alimentar $(1,47$ vs 1,51 , $P<0,01)$.

A variável conversão alimentar do contraste 4 foi melhor para 0 tratamento OAS2/SOJA2 em relação ao tratamento OAS4 (1,48 vs 1,52 , $P<0,06)$.

No contraste 2 a viabilidade foi superior $1,9 \%$ no tratamento SOJA4 em relação aos tratamentos OAS2/SOJA2 e SOJA2/SEBO2 (99,5 vs 97,6\%, $P<0,01)$. No contraste 3 a viabilidade foi superior $2,9 \%$ no tratamento OAS2/SOJA2 em relação ao tratamentos SOJA2/SEBO2 (99,1 vs $96,2 \%$, $P<0,01)$. 
Tabela 12: Médias dos tratamentos para consumo de ração (CR), ganho de peso das aves (GP), conversão alimentar (CA) e viabilidade (VB) de 1 a 28 dias de idade.

\begin{tabular}{lcccc}
\hline Tratamentos & CR $(\mathrm{kg})$ & GP $(\mathrm{kg})$ & $\mathrm{CA}$ & $\mathrm{VB}(\%)$ \\
\hline OAS4 & 1,936 & 1,271 & 1,52 & 98,7 \\
SEBO4 & 1,947 & 1,270 & 1,53 & 99,1 \\
SOJA4 & 1,900 & 1,291 & 1,47 & 99,5 \\
OAS2/SEBO2 & 1,919 & 1,275 & 1,50 & 99,1 \\
OAS2/SOJA2 & 1,923 & 1,291 & 1,48 & 99,1 \\
SOJA2/SEBO2 & 1,910 & 1,295 & 1,47 & 96,2 \\
\hline C.V.(\%) & 2,13 & 2,12 & 2,00 & 1,31 \\
\hline
\end{tabular}

C.V $(\%)$ - coeficiente de variação

Tabela 13: Contrastes e níveis de significância para cada variável de 1 a 28 dias de idade

\begin{tabular}{ccccc}
\hline Contrastes & CR $(\mathrm{kg})$ & GP $(\mathrm{kg})$ & $\mathrm{CA}$ & $\mathrm{VB}(\%)$ \\
\hline 1 & $\mathrm{P}<0,08$ & n.s. & $\mathrm{P}<0,01$ & n.s. \\
2 & n.s. & n.s. & n.s. & $\mathrm{P}<0,01$ \\
3 & n.s. & n.s. & n.s. & $\mathrm{P}<0,01$ \\
4 & n.s. & n.s. & $\mathrm{P}<0,06$ & n.s. \\
5 & n.s. & n.s. & n.s. & n.s. \\
\hline
\end{tabular}


Tabela 14: Médias dos tratamentos para consumo de ração (CR), ganho de peso das aves (GP), conversão alimentar (CA) e viabilidade (VB) de 1 a 35 dias de idade.

\begin{tabular}{lcccc}
\hline Tratamentos & CR $(\mathrm{kg})$ & GP $(\mathrm{kg})$ & CA & VB (\%) \\
\hline OAS4 & 3,103 & 1,921 & 1,61 & 97,9 \\
SEBO4 & 3,096 & 1,913 & 1,61 & 98,7 \\
SOJA4 & 3,047 & 1,951 & 1,56 & 99,1 \\
OAS2/SEBO2 & 3,108 & 1,901 & 1,63 & 98,7 \\
OAS2/SOJA2 & 3,075 & 1,944 & 1,58 & 99,1 \\
SOJA2/SEBO2 & 3,054 & 1,938 & 1,57 & 96,2 \\
\hline C.V.(\%) & 2,48 & 2,20 & 2,83 & 1,68 \\
\hline C.V $(\%)-$ coeficiente de variação & & &
\end{tabular}

Tabela 15: Contrastes e niveis de significância para cada variável de 1 a 35 dias de idade.

\begin{tabular}{ccccc}
\hline Contrastes & CR $(\mathrm{kg})$ & GP $(\mathrm{kg})$ & $\mathrm{CA}$ & VB $(\%)$ \\
\hline 1 & $\mathrm{P}<0,04$ & n.s. & $\mathrm{P}<0,01$ & n.s. \\
2 & n.s. & n.s. & n.s. & n.s. \\
3 & n.s. & n.s. & n.s. & $\mathrm{P}<0,01$ \\
4 & n.s. & n.s. & n.s. & n.s. \\
5 & n.s. & n.s. & n.s. & n.s. \\
\hline
\end{tabular}

Os resultados de desempenho obtidos de 1 a 35 dias de idade são apresentados na Tabela 14 e a análise dos contrates na Tabela 15. No contraste 1 o tratamento SOJA4 apresentou um consumo de ração 1,7\% inferior a média dos tratamentos OAS4, SEBO4, OAS2/SEBO2 $(3,047$ vs $3,102 \mathrm{~kg}$, $P<0,04)$, acompanhada de uma melhor conversão alimentar $(1,56$ vs 1,61 , $P<0,01)$. 
No contraste 3 a viabilidade se manteve superior $2,9 \%$ para o tratamento OAS2/SOJA2 em relação ao tratamentos SOJA2/SEBO2 (99,1 vs 96,2 , $\mathrm{P}<0,01)$.

Tabela 16: Médias dos tratamentos para consumo de ração $(C R)$, peso vivo das aves (PV), ganho de peso das aves (GP), conversão alimentar (CA), viabilidade (VB) e fator de produção (FP) de 1 a 42 dias de idade.

\begin{tabular}{lcccccc}
\hline Tratamentos & CR $(\mathrm{kg})$ & PV $(\mathrm{kg})$ & GP $(\mathrm{kg})$ & CA & FP & VB (\%) \\
\hline OAS4 & 4,508 & 2,647 & 2,604 & 1,73 & 350,8 & 97,9 \\
SEBO4 & 4,522 & 2,640 & 2,597 & 1,74 & 349,4 & 98,3 \\
SOJA4 & 4,466 & 2,692 & 2,649 & 1,68 & 370,7 & 98,7 \\
OAS2/SEBO2 & 4,557 & 2,663 & 2,620 & 1,73 & 351,5 & 97,5 \\
OAS2/SOJA2 & 4,480 & 2,689 & 2,646 & 1,69 & 369,4 & 99,1 \\
SOJA2/SEBO2 & 4,473 & 2,687 & 2,644 & 1,69 & 357,0 & 95,8 \\
\hline C.V.(\%) & 1,73 & 1,26 & 1,38 & 1,35 & 2,67 & 2,08 \\
\hline
\end{tabular}

C.V $(\%)$ - coeficiente de variação

Tabela 17: Contrastes e niveis de significância para cada variável, de 1 a 42 dias de idade.

\begin{tabular}{ccccccc}
\hline Contrastes & CR $(\mathrm{kg})$ & $\mathrm{PV} \mathrm{kg})$ & $\mathrm{GP}(\mathrm{kg})$ & $\mathrm{CA}$ & $\mathrm{FP}$ & $\mathrm{VB}(\%)$ \\
\hline 1 & $\mathrm{P}<0,06$ & $\mathrm{P}<0,04$ & $\mathrm{P}<0,01$ & $\mathrm{P}<0,01$ & $\mathrm{P}<0,01$ & n.s. \\
2 & n.s. & n.s. & n.s. & n.s. & n.s. & n.s. \\
3 & n.s. & n.s. & n.s. & n.s. & n.s. & $\mathrm{P}<0,02$ \\
4 & n.s. & $\mathrm{P}<0,01$ & $\mathrm{P}<0,01$ & $\mathrm{P}<0,01$ & $\mathrm{P}<0,01$ & n.s. \\
5 & n.s. & n.s. & n.s. & n.s. & n.s. & n.s.
\end{tabular}

Os resultados de desempenho obtidos de 1 a 42 dias de idade são apresentados na Tabela 16 e a análise dos contrates na Tabela 17. No contraste 1 o tratamento SOJA4 apresentou um consumo de ração $1,4 \%$ inferior a média dos tratamentos OAS4, SEBO4, OAS2/SEBO2 $(4,466$ vs $4,529 \mathrm{~kg}$, 
$\mathrm{p}<0,06$ ), assim como o peso vivo das aves e o ganho de peso foram superiores $1,6 \%$ (2,692 vs $2,650, P<0,04$ e 2,649 vs $2,607 \mathrm{~kg}, P<0,01$, respectivamente), acompanhados de melhores conversão alimentar e fator de produção $(1,68$ vs $1,73, P<0,01$ e 370,7 vs $350,5, P<0,01$, respectivamente).

No contraste 4 o peso vivo das aves e o ganho de peso foram superiores $1,6 \%$ para o tratamento OAS2/SOJA2 em relação ao tratamento OAS4 $(2,689$ vs $2,647, P<0,01$ e 2,646 vs $2,604 \mathrm{~kg}, P<0,01$, respectivamente), acompanhados de melhores conversão alimentar e fator de produção $(1,69$ vs $1,73, P<0,01$ e 369,4 vs $350,8, P<0,01$, respectivamente).

No contraste 3 a viabilidade foi superior $3,3 \%$ no tratamento OAS2/SOJA2 em relação ao tratamento SOJA2/SEBO2 (99,1 vs $95,8 \%$, $\mathrm{P}<0,02)$.

Em todas as semanas houve efeito de blocos $(P<0,05)$ para as variáveis estudadas, alternando-se entre 0 consumo de ração, ganho de peso e conversão alimentar, o que justificaria a utilização do delineamento em blocos casualizados.

Os coeficientes de variação das variáveis nas primeiras semanas apesar de estarem um pouco elevados, são considerados toleráveis, visto que foram reduzindo semanalmente até atingirem valores considerados ótimos, mostrando a boa condução do experimento.

O tratamento SOJA4 resultou em melhor desempenho durante todo periodo de criação das aves, principalmente a conversão alimentar que foi melhor desde a primeira semana de idade, alternando semanalmente menor consumo de ração ou maior ganho de peso em relação a média dos tratamentos OAS4, SEBO4 e OAS2/SEBO2. Os resultados obtidos pela comparação destes tratamentos, mostram que o óleo de soja superou, em termos de desempenho, as fontes óleo ácido de soja, sebo bovino e a mistura destes. Provavelmente, as fontes alternativas utilizadas não possuem características adequadas no que se refere a quantidade suficiente de triglicerídios para ativar todo processo de secreção de bile e formação de 
micelas, isto é, no caso do óleo ácido de soja possuir apenas ácidos graxos livres. No caso do sebo bovino, provavelmente houve um desequilibrio na proporção de ácidos graxos saturados e insaturados, comprometendo a absorção de gordura. Com isso, a energia provida pelas gorduras alternativas para aves fica reduzida, elevando o consumo de ração ou reduzindo o ganho de peso das aves, como relatado neste experimento.

No caso do óleo ácido de soja uma explicação plausivel para seu inferior desempenho em relação ao óleo de soja, seriam os elevados níveis de ácidos graxos livres, que estão diretamente ligados à falta de triglicerídios nesta fonte, para ativar a secreção de bile para a formação das micelas.

O aumento dos níveis de ácidos graxos livres reduzindo a digestibilidade e a disponibilidade de energia da gordura foi descrita por Young (1961), Wiseman \& Salvador (1991), Blanch et al. (1995) e Vila \& Garcia (1996).

Já Waldroup et al. (1995) não encontraram diferenças significativas no desempenho de frangos aos 42 dias de idade, quando utilizaram os niveis de $29,8 \%$ e $44,7 \%$ de $A G L$, provavelmente devido aos baixos níveis de $A G L$ inclusos na ração, pois Young (1961) apenas obteve diferença significativa na digestibilidade quando utilizou $95 \%$ de $A G L$ na dieta.

O sebo bovino é conhecido como fonte rica em ácidos graxos saturados e uma das prováveis explicações dada ao seu resultado inferior, em relação ao óleo de soja, seja não prover uma proporção adequada entre os ácidos graxos saturados e insaturados, acarretando numa menor absorção de gordura. Segundo Renner \& Rill (1961), os ácidos graxos saturados palmítico e esteárico tiveram uma absorção de $30 \%$ e $20 \%$, respectivamente, quando se utilizou uma mistura que continha $50 \%$ de ácidos graxos insaturados. Quando se passou para $62 \%$ de ácidos graxos insaturados na mistura a absorção do palmítico e esteárico foi de $51 \%$ e $36 \%$, respectivamente. Com $76 \%$ de ácidos graxos insaturados a absorção foi de $84 \%$ e $78 \%$ para o palmítico e o esteárico, respectivamente. 
Até o momento comentou-se apenas a respeito das gorduras sendo utilizadas como fonte única adicionadas nas rações e seus prováveis problemas de absorção, já conhecidos na literatura. O ponto de maior interesse a ser discutido neste trabalho são os resultados obtidos com as misturas das fontes utilizadas.

A mistura OAS2/SEBO2 foi primeiramente inserida no contraste 1, junto com OAS4 e SEBO4, para uma comparação de desempenho com o tratamento SOJA4. Os resultados mostraram a superioridade do óleo de soja em relação média do tratamentos com óleo ácido de soja, sebo bovino e a mistura de óleo ácido de soja e sebo. Quando se comparou o OAS4 e OAS2/SEBO2 não se observou diferença de desempenho entre estes tratamentos; provavelmente a falta de triglicerídios do óleo ácido de soja não foi suprida pelo sebo bovino, e nem a falta de ácidos graxos insaturados do sebo foi suprida pelo óleo ácido de soja. A intenção de se fazer esta mistura seria amenizar o problema de ácidos graxos livres, com os triglicerídios contidos no sebo e alterar a proporção de ácidos graxos saturados e insaturados do sebo bovino para melhor absorção. Já Sibbald et al. (1961) misturaram $50 \%$ de óleo soja que continha $15 \%$ dos ácidos graxos palmítico e esteárico, $27,2 \%$ do ácido graxo oleico, $49,8 \%$ de linoleico e $7,5 \%$ de linolênico, com $50 \%$ de sebo bovino que continha $44 \%$ de ácidos graxos palmítico e esteárico, 41,5 de oleico, $7,5 \%$ de linoleico e $0,1 \%$ de linolênico e observaram o aumento da digestibilidade do sebo misturado em relação ao sebo como fonte única de gordura em rações de frangos.

Artman (1964) obteve diferenças significativas $(P<0,05)$ na digestibilidade do óleo de soja, quando comparado com óleo ácido de soja, sebo bovino e mistura de $1: 1$ entre sebo e óleo ácido de soja, adicionados $15 \%$ a ração das aves . A digestibilidade do óleo de soja foi de $95 \%$, enquanto a do óleo ácido foi de $86,2 \%$, do sebo, $68,2 \%$ e da mistura, $87 \%$. Porém a ausência de diferença na comparação OAS4 vs OAS2/SEBO2 é uma indicação que a melhoria da absorção da mistura óleo ácido de soja e sebo não ocorreu neste trabalho e 
que a energia provida por estas gorduras, provavelmente não foram suficientes para se obter um desempenho equivalente ao óleo de soja.

A mistura SOJA2/SEBO2 foi comparada juntamente com OAS2/SOJA2 com o tratamento SOJA4 no contraste 2 enquanto no contraste 3 , foi realizada a comparação entre estas misturas que continham em comum o óleo de soja. Em ambos contrastes não houve diferença no CR, GP, CA e FP. A comparação realizada no contraste 4 mostrou a superioridade do desempenho da mistura OAS2/SOJA2 em relação ao OAS4, enquanto no contraste 5 o tratamento OAS4 não mostrou diferença de desempenho quando comparado ao OAS2/SEBO2.

A comparação dos tratamentos nos quatro contrastes citados acima mostra melhora na absorção da fontes alternativas quando misturadas ao óleo de soja (contrastes 2,3 e 4 ), devido talvez ao fornecimento de quantidade ideais de triglicerídios que atuariam na secreção de bile. No entanto, se a secreção de bile e formação de micelas estivessem ligados apenas a quantidade de triglicerídios nas gorduras, a adição de sebo bovino ao óleo ácido de soja, também seria suficiente. Entretanto, este fato não ocorreu, como mostra o contraste 5 , pressupondo que pode haver outro fator ligado a este mecanismo.

A hipótese anterior pode ser explicada pelo óleo de soja que além de prover trigliceridios, também provê ácidos graxos insaturados, enquanto que 0 sebo bovino também fornece triglicerídios, mas com ácidos graxos saturados. Supõe-se que não basta apenas ter ácidos graxos insaturados ou triglicerídios isoladamente, e sim ácidos graxos insaturados ligados ao glicerol formando os trigliceridios, caso encontrado no óleo de soja.

Levando-se esta suposição em consideração fica explicado o desempenho semelhante das aves com o fornecimento da mistura óleo ácido de soja e sebo bovino em relação ao óleo ácido, assim como a superioridade do óleo de soja e as misturas que o contêm, em relação às demais gorduras. 
Além da avaliação de desempenho das aves perante o fornecimento de diferentes fontes de gordura, há a necessidade de se avaliar as conseqüências da utilização dessas gorduras nas carcaças.

Os resultados obtidos da gordura abdominal, expresso em porcentagem do peso vivo, são mostrado na Tabela 18.

Tabela 18: Médias de tratamentos da gordura abdominal de frangos de corte, em $\%$ do peso vivo .

\begin{tabular}{cc}
\hline Tratamentos & Gordura abdominal (\% peso vivo) \\
\hline OAS4 & 2,12 \\
SEBO4 & 1,64 \\
SOJA4 & 1,65 \\
OAS2/SEBO2 & 2,08 \\
OAS2/SOJA2 & 1,93 \\
SOJA2/SEBO2 & 1,57 \\
\hline C.V.(\%) & 19,8
\end{tabular}

C.V (\%) - coeficiente de variaçấo

Os contrastes foram analisados e não houve qualquer diferença $(P>0,10)$. A Tabela 19 apresenta o perfil de ácidos graxos das gordura utilizadas nas rações experimentais e a Tabela 20, o perfil de ácidos graxos das gorduras abdominais. 
Tabela 19: Perfil de ácidos graxos das fontes de gordura, em \% ácidos graxos totais.

\begin{tabular}{lccc}
\hline \multirow{2}{*}{ Ácidos graxos } & \multicolumn{3}{c}{ \% ácidos graxos totais } \\
\cline { 2 - 4 } & Óleo de soja & Óleo ácido de soja & Sebo bovino \\
\hline $12: 0$ & 0,03 & 0,31 & 3,19 \\
$14: 0$ & 0,07 & 0,75 & 6,47 \\
$16: 0$ & 9,98 & 10,47 & 23,62 \\
$18: 0$ & 11,53 & 2,42 & 9,55 \\
$18: 1 \omega 9$ & 12,62 & 25,75 & 27,88 \\
$18: 2 \omega 6$ & 52,33 & 44,35 & 2,83 \\
$18: 3 \omega 3$ & 9,20 & 3,67 & 0,65 \\
$18: 4 \omega 3$ & - & 1,42 & 0,39 \\
Saturados & 21,61 & 13,95 & 46,87 \\
Insaturados & 74,70 & 77,59 & 39,80 \\
\hline
\end{tabular}

Como foi feita apenas uma análise de perfil de ácidos graxos por tratamento, representando 6 aves por amostra, os resultados não foram analisados estatisticamente, entretanto alguns comentários podem ser feitos sobre as alterações da composição de ácidos graxos das gorduras. 
Tabela 20: Perfil de ácidos graxos das gorduras abdominais, em \% ácidos graxos totais.

\begin{tabular}{lcccccc}
\hline & \multicolumn{6}{c}{$\%$ ácidos graxos totais } \\
\cline { 2 - 7 } Ácidos graxos & OAS4 & SEBO4 & SOJA4 & OAS2I & OAS2I & SOJA2I \\
& 2,24 & 6,91 & 7,80 & 6,14 & 5,75 & 0,17 \\
\hline $12: 0$ & 2,36 & 6,73 & 2,72 & 5,15 & 3,08 & 1,06 \\
$14: 0$ & 23,83 & 20,09 & 17,30 & 25,08 & 24,09 & 19,30 \\
$16: 0$ & 2,50 & 1,39 & 1,17 & 1,88 & 2,25 & 4,69 \\
$18: 0$ & 16,78 & 15,78 & 14,28 & 15,67 & 15,99 & 31,74 \\
$18: 1 \omega 9$ & 25,35 & 12,74 & 24,11 & 15,27 & 24,31 & 26,46 \\
$18: 2 \omega 6$ & - & 1,18 & 2,04 & 0,99 & 1,32 & - \\
$18: 3 \omega 3$ & 3,15 & 1,40 & 3,75 & 1,45 & 2,84 & 3,59 \\
$18: 4 \omega 3$ & 31,78 & 39,41 & 30,93 & 41,01 & 37,09 & 25,80 \\
Saturados & 57,17 & 47,18 & 56,84 & 50,35 & 55,82 & 68,49 \\
Insaturados & & & & & & \\
\hline
\end{tabular}

O ácido graxo linoléico $(18: 2 \omega 6)$ acumulou-se mais na gordura abdominal das aves alimentadas com fonte ricas neste ácido graxo, como óleo de soja e o óleo ácido de soja, exceto para os tratamentos SEBO4 e OAS2/SEBO2 que foram inferiores, provavelmente devido o sebo conter baixos niveis de ácido linoléico.

O ácido graxo oleico $(18: 1 \omega 9)$ manteve sua composição constante em todas as gorduras abdominais, com exceção na mistura SOJA2/SEBO2 que apresentou o dobro de ácido graxo oleico em relação aos outros tratamentos.

Neste trabalho avaliou-se apenas a quantidade de gordura abdominal acumulada na carcaça e a alteração da composição de ácidos graxos nesta gordura, porém vários pesquisadores avaliaram a composição da carcaça das aves. Edwards Jr et al. (1973) determinaram a influência da alimentação de vários tipos de gordura, entre elas, o sebo bovino e o óleo de vísceras de aves, 
na composição de ácidos graxos da carcaça e gordura abdominal. Apesar do tipo de gordura utilizado na dieta não ter influenciado a composição corporal das aves, alterou a composição dos ácidos graxos da carcaça e da gordura abdominal. A alimentação com sebo bovino elevou o conteúdo de ácidos graxos esteárico e oleico do tecido adiposo, enquanto que o óleo de vísceras de aves reduziu o ácido graxo linoleico e aumentou o oleico da gordura abdominal.

Yau et al. (1991) utilizaram óleo de coco com 83\% de ácidos graxos saturados, óleo de girassol com $79 \%$ de ácido linoleico e óleo de oliva com $70 \%$ de ácido oleico, adicionados em $8 \%$ na dietas de frangos de corte, e observaram um aumento mais pronunciado destes ácidos graxos na gordura abdominal que na gordura intramuscular. Entretanto, em ambos os tecidos as porcentagens de proteína, lipídios e matéria seca não sofreram alterações.

Zollitsch et al. (1996) utilizaram várias fontes de gordura suplementadas às dietas de frangos de corte para avaliar as alteraçōes ocorridas nas carcaças. As fontes utilizadas foram o óleo de soja, o óleo de colza e duas misturas de óleos, sendo que uma continha elevados niveis de ácidos graxos insaturados, e a outra possuía mais ácidos graxos saturados. Todas as fontes foram adicionadas em $3,5 \%$ às dietas. Não houve diferença significativa no conteúdo de gordura, proteína e matéria seca da coxa e do peito das aves. A composição de ácidos graxos da gordura abdominal foi influenciada pelas fontes de gordura, pois no caso do óleo de soja o conteúdo de ácidos graxos insaturados foi maior em relação às outras fontes, assim como a mistura de gordura rica em ácidos graxos saturados resultou em maior concentração destes na gordura abdominal das aves.

Portanto as alteraçōes ocorridas na gordura abdominal, assim como na intramuscular poderiam alterar o ponto de fusão, com conseqüências na consistência da gordura. Neste caso, os ácidos graxos saturados, que possuem maior ponto de fusão, quando presentes nas gorduras, podem deixá-las mais sólidas. Inversamente, a presença de ácidos graxos insaturados nas gorduras 
deixam-nas menos sólidas e susceptiveis a oxidação, o que resultaria em problemas de processamento e conservação desses produtos. 


\section{CONCLUSÕES}

- O desempenho obtido pelas aves com a adição de óleo de soja às rações foi superior ao óleo ácido de soja, sebo bovino e a mistura destes;

- A adição de óleo de soja em misturas com partes iguais de óleo ácido de soja ou sebo bovino, resultaram em desempenho equivalente ao obtido com o óleo de soja adicionado isoladamente;

- A mistura de óleo de soja ao óleo ácido de soja melhorou o desempenho das aves em relação ao óleo ácido de soja adicionado unicamente;

- A adição das diferentes fontes de gordura às rações, não alterou a quantidade de gordura abdominal acumulada;

- A composição dos ácidos graxos da gordura abdominal apresentou alteraçōes, conforme a adição de diferentes gorduras às raçōes. 


\section{REFERÊNCIAS BIBLIOGRÁFICAS}

ARELLANO, D.B.. Utilização de óleos e gorduras em rações avícolas: características dos produtos disponiveis no mercado. In: ANAIS CONFERÉNCIA APINCO 1992 de CIENNCIA e TECNOLOGIA AVÍCOLA, Santos, 1992. Anais. Santos: FACTA, 1992. p. 21-27.

ARTMAN, N.R. Interactions of fats and fatty acids as energy sources for the chick. Poultry Science, v. 43, p.994-1001, 1964.

BLANCH, A.; BARROETA, A. C.; BAUCELLS, M. D.; et al. The nutritive value of dietary fats in relation to their chemical composition. Apparent fat availability na metabolizable energy in two week old chicks. Poultry Science, v.74, p.1335 - 1340, 1995.

CAREW, L.B.; MANCHEMER, R.M.; SHARP, R.W.; et al. Fat absorption by the very young chick. Poultry Science, v.51, p. $738-742,1972$.

DEATON, J.W.; LOTT, B.D. Age and dietary effect on broiler abdominal fat deposition. Poultry Science, v. 64, p.2161-2164, 1985.

EDWARDS Jr., H.E.; DENMAN, F.; ASHOUR, A.A.; et al. Carcass composition studies. 1. Influences of age, sex and type of dietary fat supplementation on total carcass and fatty acid composition. Poultry Science, v. 52, p.934-948, 1973. 
FIRMAN, J. D; REMUS, J. C. Fat additions increase digestibility of meat and bone meal. Journal of Applied Poultry Research, v. 3, p. 80-82, 1994.

GARRETT, R. L; YOUNG, R. J. Effect of micelle formation on the absorption of neutral fat and fatty acids by the chicken. Journal of Nutrition, v. 105, p.827-838, 1975.

GOMEZ, M.X.; POLIN, D. The use of bile salts to improve absorption of tallow in chicks, one to three weeks of age. Poultry Science, v.55, p.2189-2195, 1976.

HRDINKA, C.; ZOLLITSCH, W.; KNAUS, W.; et al. Effests of dietary fatty acid pattern on melting pont and composition of adipose tissues and intramuscular fat of broiler carcasses. Poultry Science, v. 75, p.208-215, 1996.

JANK, S. M. Tendências do Agribusiness e do sistema agroindustrial das carnes no Brasil. In: ANAIS $5^{\circ}$ ENCONTRO DE NUTRIÇÃO ANIMAL.. Campinas, 1998. Anais. Campinas: Degussa, 1998.

KEREN, S.Z.; NIR, Z.; NITSAN, Z.; et al. Effect of dietary concentratins of fat and energy on fat deposition in brolirer divergently selected for high or low abdominal adipose tissue. Bristish. Poultry Science, v. 31, p.507-516, 1990.

KETELS, E.; DE GROOTE, G. Effect of ratio of unsaturated to saturaded fatty acids of the dietary lipid fraction on utilization and metabolizable energy of added fats in young chicks. Poultry Science, v.68, p.1506-1512, 1989. 
KETELS,E.; DE GROOTE, G. The nutritional value for broiler of fats characterized by short chain fatty acids as affected by level of inclusion and age. Animal Feed Science and Technology, v. 22, p.105-118, 1988.

KROGDAHL, A. Digestion and absorption of lipid in poultry. Journal of Nutrition, v.115, p.675-685, 1985.

MATEOS, G.G.; SELL, J.L. Metabolizable energy of supplemental fat as related to dietary fat level and methods of estimation. Poultry Science, v. 60, p.1509-1515, 1981.

MATEOS, G.G.; SELL, J.L. True and apparent metabolizable energy value of fat for laying hens: influence of level of use. Poultry Science, v. 59, p.369$373,1980$.

MAYNARD, L. A.; LOOSLI, J.K.; HINTZ, H.F.; et al. Nutrição animal. $3^{\text {a }}$ ed. Rio de Janeiro: Livraria Freitas Bastos, 1984. cap. 7, p.121 -159: Os lipídios e seu metabolismo.

MORAN, E.D.J. Fisiologia da digestão e absorção das aves. Coleção FACTA, 1994. p 71-82: Digestão e absorção de gorduras.

MORAN, E.T.; VIEIRA, S.L. A composição e a quantidade de gordura nas dietas afetam a eficiência alimentar das aves. In: II ENCONTRO DE NUTRICIONISTAS, Santiago, 1996. Anais. Santiago: Pfizer, 1996. p. 18-21.

NATIONAL RESEARCH CONCIL. Nutrient requirements of poultry. 9. ed. Washington, D. C.: National Academy Press, 1994. 71p. 
NOY, Y.; SKLAN, D. Digestion and absorption in the young chick. Poultry Science, v.7, p.366 - 373, 1995.

OLOMU, J.M.; BARACOS, V.E. Influence of dietary flaxseed oil on the performance, muscle protein deposition, and fatty acid composition of broiler chicks. Poultry Science, v. 70, p.1403-1411, 1991.

PEEBLES, E.D.; BRAE, J.D.; LATOUR, M.A. Broiler performance, yield, and characteristics as affected by starter diet fat level. Journal Applied Poultry Research, v.6, p.325 - 330, 1997.

PENZ Jr., A. M.; VIEIRA, S.L. Nutrição na primeira semana. In: CONFERÊNCIA APINCO'98 DE CIÊNCIA E TECNOLOGIA AVICOLAS, Campinas, 1998. Anais. Campinas: FACTA, 1998. p. 121-138.

RENNER, R.; HILL, F.W. Factors affecting the absorbability of sturated fatty acids in the chick. Journal of Nutrition, v.74, p.254-258, 1961.

ROSTAGNO, H.S; BARBARINO, Jr. P; BARBOSA, W.A. Exigências nutricionais das aves determinadas no Brasil. In: SIMPÓSIO SOBRE EXIGÊNCIAS NUTRICIONAIS DE AVES E SUÍNOS, Viçosa,1996. Anais. Viçosa: Rostagno, H.S. (ED.), 1996. p. 361-388.

RUTZ, F. Fisiologia da digestão e absorção das aves. Coleção FACTA, 1994. p 83-98: Absorção de minerais e vitaminas.

SANZ, M.;FLORES, A.; LOPEZ, B. C. J. Effect of fatty acid saturation in broiler diets on abdominal fat and breast muscle fatty acid composition and susceptibility to lipid oxidation. Poultry Science, v.78, p. 378-382, 1999. 
SAS Institute Inc. (1989), SAS/STAT User's Guide, version 6, Fourth Edition, Cary, NC:SAS Institute Inc.

SCOTT, M.L.; NESHEIM, M.C.; YOUNG, R.J. Nutrition of the chicken. 3.ed. New York: M. L. Scott Associates, 1982. cap.2, p 7-57: Energy.

SIBBALD, I.R.; KRAMER, J.K.G. Effect of the basal diet on the utilization of fat as a sources of true metabolizable energy, lipid and fatty acid. Poultry Science, v. 59, p. 316-324, 1980a.

SIBBALD, I.R.; KRAMER, J.K.G. The effects of fractions of yellow corn on the true metabolizable energy value of beef tallow. Poultry Science, v. 59, p. 1505-1509, 1980b.

SIBBALD, I.R.; SLINGER, S.J. A biological assay for metabolizable energy in poultry feed ingredients together with findings which demonstrate some of the problems associated with the evaluation of fats. Poultry Science, v.42, p. $313-325,1963$.

SIBBALD, I.R.; SLINGER, S.J.; ASHTON, G.C. Factors affeting the metabolizable energy content of poultry feeds. 2. Variability in the M.E. values attributed to samples of tallow, and undeummed soybean oil. Poultry Science, v.40, p.303-308, 1961.

SKLAN, D. Digestion na absortion of lipids in chicks fed triglycerides or free fatty acids: synthesis of monoglycerides in the intestine. Poultry Science, v. 58, p. $885-889,1979$.

TORRES, A.P. Alimentação e nutrição das aves domésticas. 2.ed. São Paulo: Livraria Nobel, 1979. cap.6, p.123-133: As graxas. 
VILA, B.; GARCIA, E.E. Studies on acid oils and fatty acids for chickens. III. Effect of chemical composition on metabolizable energy of by-products of vegetable oil refining. British Poultry Science, v.37, p.131-144, 1996.

WALDROUP, P. W.; WATKINS, S. E.; SALEH, E. A. Comparison of two blended animal-vegetable fats having low or high free fatty acid content. Journal of Applied Poultry Research, v. 4, p. 41-48, 1995.

WISEMAN, J.; COLE, D.J.A.; PERRY, F.G.; et al. Apparent metabolizable energy values of fats for broiler chicks. Bristish Poultry Science, v. 27, p.561-576, 1986.

WISEMAN, J.; SALVADOR, F. Influence of age, chemical composition and rate of inclusion on the apparent metabolizable energy of fats fed to broiler chicks. British Poultry Science, v.30, p.653 - 662, 1989.

WISEMAN, J.; SALVADOR, F. The influence of free fatty acid content and degree of saturation on the apparent metabolizable energy value of fats fed to broilers. Poultry Science, v. 70, p. 573-582, 1991.

YAU,J.C.; DENTON, J.H.; BAILEY, C.A.; et al. Customizing the fatty acid content of broiler tissues. Poultry Science, v. 70, p.167-172, 1991.

YOUNG, R. J. The energy value of fats and fatty acids for chicks. 1. Metabolizable energy. Poultry Science, v. 40, p. 1225 - 1233, 1961.

YOUNG, R. J.; GARRETT, R. L. Effect of oleic and linoleic acids on the absorption of saturated fatty acids in the chick. Journal of Nutrition, v. 81 , p.321-329, 1963. 
YOUNG, R.J.; ARTMAN N.R. The energy value of fats and fatty acids for chicks. 2. Evaluted by controlled feed intake. Poultry Science, v. 40, p. 1653-1662, 1961.

ZOLLITSCH, W.; KNAUS, W.; AICHINGER, F.; et al. Effects of different dietary and carcass characteristics of broiler. Animal Feed Science and Technology, v.66, p.63-73, 1997.

ZUMBADO, E.M.; SCHEELE, C.R.; KWAKERNAAK, C. Chemical composition, digestibility, and metabolizeble energy content of different fat and oil byproducts. Journal Applied Poultry Research, v.8, p.263 - 271, 1999. 


\section{APÊNDICE}


Apêndice 1: Consumo de ração acumulado por parcela e médias de tratamentos.

\begin{tabular}{|c|c|c|c|c|c|c|}
\hline \multicolumn{7}{|c|}{ Consumo de ração (kg) } \\
\hline Tratamentos & 7 & 14 & 21 & 28 & 35 & 42 \\
\hline \multirow{6}{*}{ OAS4 } & 0,135 & 0,458 & 0,968 & 1,843 & 2,968 & 4,403 \\
\hline & 0,151 & 0,489 & 1,037 & 1,984 & 3,112 & 4,512 \\
\hline & 0,140 & 0,483 & 1,068 & 1,948 & 3,096 & 4,473 \\
\hline & 0,140 & 0,474 & 1,015 & 1,925 & 3,139 & 4,534 \\
\hline & 0,152 & 0,490 & 1,065 & 1,962 & 3,192 & 4,610 \\
\hline & 0,160 & 0,489 & 1,031 & 1,955 & 3,112 & 4,499 \\
\hline Média & 0,146 & 0,480 & 1,031 & 1,936 & 3,103 & 4,508 \\
\hline \multirow{6}{*}{ SEBO4 } & 0,153 & 0,483 & 1,016 & 1,896 & 3,098 & 4,479 \\
\hline & 0,139 & 0,470 & 1,015 & 1,898 & 3,098 & 4,492 \\
\hline & 0,152 & 0,497 & 1,053 & 1,935 & 2,876 & 4,394 \\
\hline & 0,162 & 0,496 & 1,079 & 1,979 & 3,166 & 4,568 \\
\hline & 0,143 & 0,470 & 1,015 & 1,946 & 3,118 & 4,538 \\
\hline & 0,151 & 0,499 & 1,099 & 2,029 & 3,221 & 4,657 \\
\hline Média & 0,150 & 0,486 & 1,046 & 1,947 & 3,096 & 4,522 \\
\hline \multirow{6}{*}{ SOJA4 } & 0,136 & 0,453 & 1,037 & 1,901 & 3,052 & 4,452 \\
\hline & 0,134 & 0,446 & 0,951 & 1,809 & 2,941 & 4,307 \\
\hline & 0,143 & 0,461 & 1,008 & 1,878 & 2,971 & 4,371 \\
\hline & 0,147 & 0,463 & 1,018 & 1,896 & 3,111 & 4,513 \\
\hline & 0,145 & 0,470 & 1,032 & 1,937 & 3,097 & 4,602 \\
\hline & 0,159 & 0,488 & 1,071 & 1,978 & 3,113 & 4,523 \\
\hline Média & 0,144 & 0,463 & 1,019 & 1,900 & 3,047 & 4,466 \\
\hline \multirow{6}{*}{$\begin{array}{l}\text { OAS2I } \\
\text { SEBO2 }\end{array}$} & 0,151 & 0,480 & 1,027 & 1,902 & 3,030 & 4,409 \\
\hline & 0,147 & 0,463 & 0,986 & 1,865 & 3,325 & 4,695 \\
\hline & 0,134 & 0,452 & 0,982 & 1,841 & 3,203 & 4,647 \\
\hline & 0,153 & 0,476 & 1,046 & 1,936 & 3,223 & 4,654 \\
\hline & 0,157 & 0,491 & 1,063 & 1,986 & 3,231 & 4,650 \\
\hline & 0,146 & 0,482 & 1,037 & 1,984 & 3,114 & 4,505 \\
\hline Média & 0,148 & 0,474 & 1,023 & 1,919 & 3,188 & 4,557 \\
\hline \multirow{6}{*}{$\begin{array}{l}\text { OAS21 } \\
\text { SOJA2 }\end{array}$} & 0,137 & 0,477 & 1,041 & 1,911 & 3,059 & 4,468 \\
\hline & 0,142 & 0,468 & 1,011 & 1,916 & 3,013 & 4,394 \\
\hline & 0,135 & 0,469 & 0,994 & 1,859 & 3,029 & 4,419 \\
\hline & 0,134 & 0,467 & 1,037 & 1,932 & 3,094 & 4,528 \\
\hline & 0,143 & 0,478 & 1,053 & 1,948 & 3,095 & 4,447 \\
\hline & 0,164 & 0,507 & 1,062 & 1,972 & 3,162 & 4,569 \\
\hline Média & 0,142 & 0,477 & 1,033 & 1,923 & 3,075 & 4,480 \\
\hline \multirow{6}{*}{$\begin{array}{l}\text { SOJA2I } \\
\text { SEBO2 }\end{array}$} & 0,145 & 0,474 & 1,052 & 1,886 & 2,996 & 4,330 \\
\hline & 0,144 & 0,475 & 0,975 & 1,838 & 2,978 & 4,391 \\
\hline & 0,146 & 0,488 & 1,069 & 1,972 & 3,135 & 4,606 \\
\hline & 0,147 & 0,475 & 1,042 & 1,911 & 3,049 & 4,508 \\
\hline & 0,144 & 0,480 & 1,037 & 1,951 & 3,107 & 4,533 \\
\hline & 0,149 & 0,442 & 0,986 & 1,899 & 3,060 & 4,483 \\
\hline Média & 0,146 & 0,472 & 1,027 & 1,910 & 3,054 & 4,473 \\
\hline
\end{tabular}


Apêndice 2: Ganho de peso acumulado por parcela e médias de tratamentos.

\begin{tabular}{|c|c|c|c|c|c|c|}
\hline \multicolumn{7}{|c|}{ Ganho de peso $(\mathrm{kg})$} \\
\hline Tratamentos & 7 & 14 & 21 & 28 & 35 & 42 \\
\hline \multirow{6}{*}{ OAS4 } & 0,106 & 0,330 & 0,655 & 1,227 & 1,857 & 2,552 \\
\hline & 0,106 & 0,340 & 0,707 & 1,293 & 1,901 & 2,608 \\
\hline & 0,109 & 0,337 & 0,700 & 1,210 & 1,875 & 2,570 \\
\hline & 0,113 & 0,340 & 0,690 & 1,278 & 1,948 & 2,602 \\
\hline & 0,116 & 0,357 & 0,750 & 1,322 & 2,028 & 2,698 \\
\hline & 0,114 & 0,345 & 0,702 & 1,303 & 1,921 & 2,593 \\
\hline Média & 0,111 & 0,341 & 0,700 & 1,272 & 1,921 & 2,604 \\
\hline \multirow{6}{*}{ SEBO4 } & 0,115 & 0,340 & 0,700 & 1,247 & 1,915 & 2,560 \\
\hline & 0,111 & 0,342 & 0,700 & 1,247 & 1,895 & 2,572 \\
\hline & 0,111 & 0,355 & 0,713 & 1,260 & 1,890 & 2,594 \\
\hline & 0,115 & 0,332 & 0,692 & 1,220 & 1,835 & 2,527 \\
\hline & 0,112 & 0,342 & 0,720 & 1,329 & 1,965 & 2,672 \\
\hline & 0,119 & 0,360 & 0,762 & 1,325 & 1,977 & 2,670 \\
\hline Média & 0,114 & 0,345 & 0,714 & 1,271 & 1,913 & 2,599 \\
\hline \multirow{6}{*}{ SOJA4 } & 0,112 & 0,340 & 0,727 & 1,266 & 1,919 & 2,626 \\
\hline & 0,114 & 0,345 & 0,695 & 1,247 & 1,890 & 2,597 \\
\hline & 0,115 & 0,352 & 0,737 & 1,287 & 1,922 & 2,630 \\
\hline & 0,116 & 0,350 & 0,735 & 1,292 & 2,002 & 2,667 \\
\hline & 0,114 & 0,355 & 0,742 & 1,315 & 1,982 & 2,728 \\
\hline & 0,117 & 0,362 & 0,765 & 1,345 & 1,992 & 2,717 \\
\hline Média & 0,114 & 0,350 & 0,733 & 1,292 & 1,951 & 2,661 \\
\hline \multirow{6}{*}{$\begin{array}{l}\text { OAS2I } \\
\text { SEBO2 }\end{array}$} & 0,110 & 0,345 & 0,707 & 1,255 & 1,895 & 2,590 \\
\hline & 0,107 & 0,339 & 0,683 & 1,242 & 1,911 & 2,645 \\
\hline & 0,109 & 0,343 & 0,695 & 1,234 & 1,854 & 2,623 \\
\hline & 0,113 & 0,337 & 0,715 & 1,295 & 1,817 & 2,718 \\
\hline & 0,119 & 0,365 & 0,752 & 1,327 & 1,977 & 2,675 \\
\hline & 0,111 & 0,352 & 0,742 & 1,305 & 1,952 & 2,647 \\
\hline Média & 0,111 & 0,347 & 0,716 & 1,276 & 1,901 & 2,649 \\
\hline \multirow{6}{*}{$\begin{array}{l}\text { OAS2I } \\
\text { SOJA2 }\end{array}$} & 0,113 & 0,363 & 0,729 & 1,285 & 1,944 & 2,662 \\
\hline & 0,110 & 0,342 & 0,713 & 1,290 & 1,924 & 2,616 \\
\hline & 0,116 & 0,352 & 0,705 & 1,252 & 1,890 & 2,590 \\
\hline & 0,107 & 0,340 & 0,725 & 1,287 & 1,940 & 2,640 \\
\hline & 0,118 & 0,362 & 0,757 & 1,322 & 1,982 & 2,660 \\
\hline & 0,116 & 0,365 & 0,742 & 1,317 & 1,987 & 2,712 \\
\hline Média & 0,113 & 0,354 & 0,728 & 1.292 & 1,944 & 2,646 \\
\hline \multirow{6}{*}{$\begin{array}{l}\text { SOJA2I } \\
\text { SEBO2 }\end{array}$} & 0,117 & 0,347 & 0,732 & 1,265 & 1,883 & 2,670 \\
\hline & 0,109 & 0,365 & 0,694 & 1,254 & 1,915 & 2,620 \\
\hline & 0,117 & 0,376 & 0,739 & 1,320 & 1,975 & 2,704 \\
\hline & 0,118 & 0,361 & 0,744 & 1,306 & 1,972 & 2,690 \\
\hline & 0,114 & 0,345 & 0,725 & 1,316 & 1,934 & 2,629 \\
\hline & 0,107 & 0,340 & 0,724 & 1,313 & 1,949 & 2,675 \\
\hline Média & 0,114 & 0,356 & 0,726 & 1,296 & 1,938 & 2,665 \\
\hline
\end{tabular}


Apêndice 3: Conversão alimentar acumulado por parcela e médias de tratamentos.

\begin{tabular}{|c|c|c|c|c|c|c|}
\hline \multicolumn{7}{|c|}{ Conversāo alimentar } \\
\hline Tratamentos & 7 & 14 & 21 & 28 & 35 & 42 \\
\hline \multirow{6}{*}{ OAS4 } & 1,27 & 1,39 & 1,48 & 1,50 & 1,60 & 1,73 \\
\hline & 1,43 & 1,44 & 1,47 & 1,53 & 1,64 & 1,73 \\
\hline & 1,28 & 1,43 & 1,53 & 1,61 & 1,65 & 1,74 \\
\hline & 1,24 & 1,39 & 1,47 & 1,51 & 1,61 & 1,74 \\
\hline & 1,31 & 1,37 & 1,42 & 1,48 & 1,57 & 1,71 \\
\hline & 1,40 & 1,42 & 1,47 & 1,50 & 1,62 & 1,74 \\
\hline Média & 1,32 & 1,41 & 1,47 & 1,52 & 1,61 & 1,73 \\
\hline \multirow{6}{*}{ SEBO4 } & 1,33 & 1,42 & 1,45 & 1,52 & 1,62 & 1,74 \\
\hline & 1,25 & 1,38 & 1,45 & 1,52 & 1,64 & 1,75 \\
\hline & 1,36 & 1,40 & 1,48 & 1,54 & 1,52 & 1,67 \\
\hline & 1,42 & 1,49 & 1,56 & 1,62 & 1,7 & 1,80 \\
\hline & 1,28 & 1,37 & 1,41 & 1,46 & 1,59 & 1,70 \\
\hline & 1,27 & 1,39 & 1,44 & 1,53 & 1,63 & 1,74 \\
\hline Média & 1,32 & 1,41 & 1,46 & 1,53 & 1,62 & 1,73 \\
\hline \multirow{6}{*}{ SOJA4 } & 1,22 & 1,34 & 1,43 & 1,50 & 1,59 & 1,70 \\
\hline & 1,18 & 1,29 & 1,37 & 1,45 & 1,56 & 1,66 \\
\hline & 1,24 & 1,31 & 1,37 & 1,46 & 1,55 & 1,66 \\
\hline & 1,27 & 1,32 & 1,39 & 1,47 & 1,55 & 1,69 \\
\hline & 1,27 & 1,32 & 1,39 & 1,47 & 1,56 & 1,69 \\
\hline & 1,36 & 1,35 & 1,40 & 1,47 & 1,56 & 1,66 \\
\hline Média & 1,26 & 1,32 & 1,39 & 1,47 & 1,56 & 1,68 \\
\hline \multirow{6}{*}{$\begin{array}{c}\text { OAS2I } \\
\text { SEBO2 }\end{array}$} & 1,37 & 1,39 & 1,45 & 1,52 & 1,55 & 1,71 \\
\hline & 1,38 & 1,37 & 1,44 & 1,50 & 1,69 & 1,83 \\
\hline & 1,24 & 1,32 & 1,41 & 1,49 & 1,68 & 1,78 \\
\hline & 1,35 & 1,41 & 1.46 & 1,50 & 1,72 & 1,76 \\
\hline & 1,32 & 1,35 & 1,41 & 1,50 & 1,59 & 1,75 \\
\hline & 1,31 & 1,37 & 1,40 & 1,52 & 1,55 & 1,71 \\
\hline Média & 1,33 & 1,37 & 1,43 & 1,50 & 1,63 & 1,75 \\
\hline \multirow{6}{*}{$\begin{array}{l}\text { OAS2I } \\
\text { SOJA2 }\end{array}$} & 1,21 & 1,32 & 1,43 & 1,49 & 1,57 & 1,68 \\
\hline & 1,30 & 1,37 & 1,42 & 1,48 & 1,57 & 1,68 \\
\hline & 1,16 & 1,33 & 1,41 & 1,48 & 1,60 & 1,71 \\
\hline & 1,25 & 1,37 & 1,43 & 1,50 & 1,60 & 1,71 \\
\hline & 1,21 & 1,32 & 1,39 & 1,47 & 1,56 & 1,67 \\
\hline & 1,41 & 1,39 & 1,43 & 1,50 & 1,59 & 1,68 \\
\hline \multirow[t]{2}{*}{ Média } & 1,26 & 1,35 & 1,42 & 1,49 & 1,58 & 1,69 \\
\hline & 1,24 & 1,36 & 1,44 & 1,49 & 1,59 & 1,62 \\
\hline & 1,32 & 1,30 & 1,41 & 1,47 & 1,56 & 1,68 \\
\hline SOJA2I & 1,25 & 1,30 & 1,45 & 1,49 & 1,59 & 1,70 \\
\hline \multirow[t]{3}{*}{ SEBO2 } & 1,24 & 1,32 & 1,40 & 1,46 & 1,55 & 1,68 \\
\hline & 1,26 & 1,39 & 1,43 & 1,48 & 1,61 & 1,72 \\
\hline & 1,40 & 1,30 & 1,36 & 1,45 & 1,57 & 1,68 \\
\hline Média & 1,28 & 1,33 & 1,41 & 1,47 & 1,58 & 1,68 \\
\hline
\end{tabular}


Apêndice 4: Viabilidade acumulada por parcela e médias de tratamentos.

\begin{tabular}{|c|c|c|c|c|c|c|}
\hline \multicolumn{7}{|c|}{ Viabilidade (\%) } \\
\hline Tratamentos & 7 & 14 & 21 & 28 & 35 & 42 \\
\hline \multirow{6}{*}{ OAS4 } & 100,000 & 100,000 & 100,000 & 100,000 & 100,000 & 100,000 \\
\hline & 100,000 & 100,000 & 100,000 & 97,500 & 97,500 & 97,500 \\
\hline & 100,000 & 100,000 & 100,000 & 100,000 & 100,000 & 100,000 \\
\hline & 100,000 & 97,500 & 97,500 & 97,500 & 95,000 & 95,000 \\
\hline & 100,000 & 100,000 & 100,000 & 100,000 & 97,500 & 97,500 \\
\hline & 100,000 & 100,000 & 100,000 & 97,500 & 97,500 & 97,500 \\
\hline Média & 100,000 & 99,583 & 99,583 & 98,750 & 97,917 & 97,917 \\
\hline \multirow{6}{*}{ SEBO4 } & 100,000 & 100,000 & 100,000 & 100,000 & 97,500 & 97,500 \\
\hline & 100,000 & 100,000 & 100,000 & 100,000 & 100,000 & 100,000 \\
\hline & 100,000 & 97,500 & 97,500 & 97,500 & 97,500 & 95,000 \\
\hline & 100,000 & 100,000 & 100,000 & 100,000 & 100,000 & 100,000 \\
\hline & 100,000 & 100,000 & 100,000 & 97,500 & 97,500 & 97,500 \\
\hline & 100,000 & 100,000 & 100,000 & 100,000 & 100,000 & 100,000 \\
\hline Média & 100,000 & 99,583 & 99,583 & 99,167 & 98,750 & 98,333 \\
\hline \multirow{6}{*}{ SOJA4 } & 100,000 & 100,000 & 97,500 & 97,500 & 97,500 & 97,500 \\
\hline & 100,000 & 100,000 & 100,000 & 100,000 & 100,000 & 100,000 \\
\hline & 100,000 & 100,000 & 100,000 & 100,000 & 100,000 & 100,000 \\
\hline & 100,000 & 100,000 & 100,000 & 100,000 & 97,500 & 97,500 \\
\hline & 100,000 & 100,000 & 100,000 & 100,000 & 100,000 & 97,500 \\
\hline & 100,000 & 100,000 & 100,000 & 100,000 & 100,000 & 100,000 \\
\hline Média & 100,000 & 100,000 & 99,583 & 99,583 & 99,167 & 98,750 \\
\hline \multirow{6}{*}{$\begin{array}{l}\text { OAS2I } \\
\text { SEBO2 }\end{array}$} & 100,000 & 100,000 & 100,000 & 100,000 & 100,000 & 100,000 \\
\hline & 100,000 & 97,500 & 97,500 & 97,500 & 95,000 & 92,500 \\
\hline & 100,000 & 97,500 & 97,500 & 97,500 & 97,500 & 95,000 \\
\hline & 100,000 & 100,000 & 100,000 & 100,000 & 100,000 & 97,500 \\
\hline & 100,000 & 100,000 & 100,000 & 100,000 & 100,000 & 100,000 \\
\hline & 100,000 & 100,000 & 100,000 & 100,000 & 100,000 & 100,000 \\
\hline \multirow[t]{3}{*}{ Média } & 100,000 & 99,167 & 99,167 & 99,167 & 98,750 & 97,500 \\
\hline & 100,000 & 97,500 & 97,500 & 97,500 & 97,500 & 97,500 \\
\hline & 100,000 & 100,000 & 97,500 & 97,500 & 97,500 & 97,500 \\
\hline OAS2I & 100,000 & 100,000 & 100,000 & 100,000 & 100,000 & 100,000 \\
\hline \multirow[t]{3}{*}{ SOJA2 } & 100,000 & 100,000 & 100,000 & 100,000 & 100,000 & 100,000 \\
\hline & 100,000 & 100,000 & 100,000 & 100,000 & 100,000 & 100,000 \\
\hline & 100,000 & 100,000 & 100,000 & 100,000 & 100,000 & 100,000 \\
\hline Média & 100,000 & 99,583 & 99,167 & 99,167 & 99,167 & 99,167 \\
\hline \multirow{6}{*}{$\begin{array}{l}\text { SOJA2I } \\
\text { SEBO2 }\end{array}$} & 100,000 & 100,000 & 97,500 & 97,500 & 97,500 & 95,000 \\
\hline & 100,000 & 95,000 & 95,000 & 95,000 & 95,000 & 95,000 \\
\hline & 100,000 & 97,500 & 95,000 & 95,000 & 95,000 & 95,000 \\
\hline & 100,000 & 97,500 & 97,500 & 97,500 & 97,500 & 97,500 \\
\hline & 100,000 & 100,000 & 100,000 & 97,500 & 97,500 & 97,500 \\
\hline & 100,000 & 100,000 & 97,500 & 95,000 & 95,000 & 95,000 \\
\hline Média & 100,000 & 98,333 & 97,083 & 96,250 & 96,250 & 95,833 \\
\hline
\end{tabular}


Apêndice 5: Peso vivo (PV), fator de produção (FP) e gordura abdominal (PG) acumulado por parcela e médias de tratamentos aos 42 dias de idade.

\begin{tabular}{|c|c|c|c|}
\hline Tratamentos & PV & FP & $P G$ \\
\hline \multirow{6}{*}{ OAS4 } & 2,595 & 351,2 & 2,72 \\
\hline & 2,651 & 350,0 & 2,48 \\
\hline & 2,613 & 351,6 & 2,04 \\
\hline & 2,645 & 338,2 & 1,24 \\
\hline & 2,741 & 368,2 & 1,42 \\
\hline & 2,636 & 346,0 & 2,87 \\
\hline Média & 2,647 & 350,5 & \\
\hline \multirow{6}{*}{ SEBO4 } & 2,603 & 341,5 & 1,53 \\
\hline & 2,615 & 350,0 & 1,81 \\
\hline & 2,621 & 351,3 & 1,79 \\
\hline & 2,570 & 334,2 & 1,80 \\
\hline & 2,715 & 364,8 & 1,48 \\
\hline & 2,713 & 365,3 & 1,45 \\
\hline Média & 2,640 & 349,4 & \\
\hline \multirow{6}{*}{ SOJA4 } & 2,669 & 358,5 & 1,41 \\
\hline & 2,640 & 372,4 & 1,55 \\
\hline & 2,673 & 377,2 & 1,78 \\
\hline & 2,710 & 366,3 & 1,89 \\
\hline & 2,705 & 374,7 & 1,20 \\
\hline & 2,760 & 389,7 & 2,11 \\
\hline \multirow[t]{2}{*}{ Média } & 2,692 & 370,7 & \\
\hline & 2,633 & 360,6 & 2,27 \\
\hline & 2,624 & 318,8 & 1,63 \\
\hline OAS2I & 2,616 & 333,3 & 2,49 \\
\hline \multirow[t]{3}{*}{ SEBO2 } & 2,697 & 346,0 & 2,07 \\
\hline & 2,718 & 369,7 & 2,15 \\
\hline & 2,690 & 368,5 & 1,90 \\
\hline \multirow[t]{3}{*}{ Média } & 2,663 & 351,5 & \\
\hline & 2,705 & 367,8 & 1,79 \\
\hline & 2,659 & 361,4 & 2,05 \\
\hline & 2,633 & 360,6 & 1,77 \\
\hline \multirow{3}{*}{ SOJA2 } & 2,683 & 367,5 & 2,06 \\
\hline & 2,703 & 379,2 & 1,88 \\
\hline & 2,755 & 384,3 & 2,07 \\
\hline \multirow[t]{3}{*}{ Médía } & 2,689 & 369,4 & \\
\hline & 2,713 & 372,8 & 1,79 \\
\hline & 2,663 & 352,7 & 1,21 \\
\hline SOJA2I & 2,717 & 359,7 & 1,83 \\
\hline \multirow[t]{3}{*}{ SEBO2 } & 2,713 & 371,7 & 1,68 \\
\hline & 2,672 & 354,8 & 1,57 \\
\hline & 2,718 & 385,3 & 1,37 \\
\hline Média & 2,687 & 366,0 & \\
\hline
\end{tabular}


APÊNDICE 6: Análises de qualidade das gorduras.

\begin{tabular}{|l|c|c|c|c|}
\hline \multirow{2}{*}{ Análises } & \multicolumn{2}{|c|}{ Padrão } & \multicolumn{2}{c|}{ Óleo ácido de soja } \\
\cline { 2 - 5 } & Mínimo & Máximo & \multicolumn{2}{c|}{ Resultados } \\
\hline Umidade (\%) & & 1,5 & 4,08 & 5,90 \\
\hline Matéria insaponificável (\%) & & 4,0 & 7,52 & 6,48 \\
\hline Indice de peróxido (mEq/kg) & & 8,0 & 0,00 & 0,00 \\
\hline Indice de acidez (mgKOH/g) & & 160 & 142,49 & 143,52 \\
\hline Impureza (\%) & & 1,0 & 0,16 & 0,12 \\
\hline Indice de iodo & 110 & & 100,97 & 100,81 \\
\hline \multirow{2}{*}{ Análises } & Padrão & \multicolumn{2}{c|}{ Óleo de soja } \\
\cline { 2 - 5 } & Mínimo & Máximo & \multicolumn{2}{c|}{ Resultados } \\
\hline Umidade (\%) & & 1,5 & 0,14 & 0,16 \\
\hline Matéria insaponificável (\%) & & 4,0 & 1,46 & 1,46 \\
\hline Indice de peróxido (mEq/kg) & & 8,0 & 0,00 & 0,00 \\
\hline Indice de acidez (mgKOH/g) & & 160 & 1,10 & 1,40 \\
\hline Impureza (\%) & & 1,0 & 0,01 & 0,01 \\
\hline Indice de iodo & 110 & & 134,83 & 129,14 \\
\hline Análises & \multicolumn{2}{|c|}{ Padrão } & \multicolumn{2}{c|}{ Sebo bovino } \\
\hline Mínimo & Máximo & \multicolumn{2}{c|}{ Resultados } \\
\hline Umidade (\%) & & 1,5 & 0,01 & 0,04 \\
\hline Matéria insaponificável (\%) & & 4,0 & 1,10 & 1,14 \\
\hline Indice de peróxido (mEq/kg) & & 8,0 & 0,00 & 0,00 \\
\hline Indice de acidez (mgKOH/g) & & 160 & 5,53 & 5,48 \\
\hline Impureza (\%) & & 1,0 & 0,07 & 0,07 \\
\hline Indice de iodo & & & 44,19 & 42,77 \\
\hline
\end{tabular}

